\title{
3D multiple-point geostatistical simulation of joint subsurface redox and geological architectures
}

\author{
Rasmus Bødker Madsen ${ }^{1}$, Hyojin Kim ${ }^{1}$, Anders Juhl Kallesøe ${ }^{1}$, Peter B. E. Sandersen ${ }^{1}$, Troels Norvin Vilhelmsen ${ }^{2}$, \\ Thomas Mejer Hansen ${ }^{2}$, Anders Vest Christiansen ${ }^{2}$, Ingelise Møller ${ }^{1}$, and Birgitte Hansen ${ }^{1}$ \\ ${ }^{1}$ Groundwater and Quaternary Geology Mapping, Geological Survey of Denmark and Greenland, Aarhus, 8000, Denmark \\ ${ }^{2}$ Department of Geoscience, Aarhus University, Aarhus, 8000, Denmark
}

Correspondence: Rasmus Bødker Madsen (rbm@geus.dk)

Received: 28 August 2020 - Discussion started: 10 September 2020

Revised: 26 March 2021 - Accepted: 12 April 2021 - Published: 25 May 2021

\begin{abstract}
Nitrate contamination of subsurface aquifers is an ongoing environmental challenge due to nitrogen $(\mathrm{N})$ leaching from intensive $\mathrm{N}$ fertilization and management on agricultural fields. The distribution and fate of nitrate in aquifers are primarily governed by geological, hydrological and geochemical conditions of the subsurface. Therefore, we propose a novel approach to modeling both geology and redox architectures simultaneously in high-resolution 3D $(25 \mathrm{~m} \times$ $25 \mathrm{~m} \times 2 \mathrm{~m}$ ) using multiple-point geostatistical (MPS) simulation. Data consist of (1) mainly resistivities of the subsurface mapped with towed transient electromagnetic measurements (tTEM), (2) lithologies from borehole observations, (3) redox conditions from colors reported in borehole observations, and (4) chemistry analyses from water samples. Based on the collected data and supplementary surface geology maps and digital elevation models, the simulation domain was subdivided into geological elements with similar geological traits and depositional histories. The conceptual understandings of the geological and redox architectures of the study system were introduced to the simulation as training images for each geological element. On the basis of these training images and conditioning data, independent realizations were jointly simulated of geology and redox inside each geological element and stitched together into a larger model. The joint simulation of geological and redox architectures, which is one of the strengths of MPS compared to other geostatistical methods, ensures that the two architectures in general show coherent patterns. Despite the inherent subjectivity of interpretations of the training images and geological element boundaries, they enable an easy and intuitive incorporation of qualitative knowledge of geology and geochem-
\end{abstract}

istry in quantitative simulations of the subsurface architectures. Altogether, we conclude that our approach effectively simulates the consistent geological and redox architectures of the subsurface that can be used for hydrological modeling with nitrogen $(\mathrm{N})$ transport, which may lead to a better understanding of $\mathrm{N}$ fate in the subsurface and to future more targeted regulation of agriculture.

\section{Introduction}

The loss of reactive nitrogen $(\mathrm{N})$ from agricultural soils results in adverse environmental and human health impacts (Schullehner et al., 2018; Temkin et al., 2019), including eutrophication of freshwater and marine ecosystems and nitrate contamination of groundwater and drinking water (Schullehner and Hansen, 2014). In Denmark, since the 1980s N regulations of intensive agriculture at national or regional scales have succeeded in lowering the $\mathrm{N}$ impact on the aquatic environment (Dalgaard et al., 2014; Hansen et al., 2017). However, further actions are still required to improve the state of the aquatic ecosystems to meet the requirements of, e.g., the EU Water Framework Directive (European Commission, 2018; Hansen et al., 2019; Kallis and Butler, 2001). Moreover, this must be achieved in a cost-effective manner for society and the agricultural industry. This creates a demand for new knowledge and new solutions for more efficient future $\mathrm{N}$ regulation of the agricultural sector both in Denmark and in other countries with intensive agriculture. The proposed direction is to introduce more targeted $\mathrm{N}$ regulation depending on the site-specific conditions at field level. 
The targeted $\mathrm{N}$ regulations require detailed knowledge of the subsurface hydrogeological and biogeochemical conditions because nitrate, which is the dominant form of $\mathrm{N}$ in aquatic environments, is transported predominantly with water flow and undergoes reduction in reducing zones of the subsurface. Thus, it has now become increasingly important to have detailed knowledge of the subsurface geology and redox architectures.

In a simple case with only vertical infiltration, nitrate concentrations in aquifers decrease with an increasing depth along three sequential redox zones (Kim et al., 2019; Wilson et al., 2018).

1. Oxic zone: nitrate concentrations are equal to the leaching from the soil because of the oxic conditions preventing reduction.

2. N-reducing zone: nitrate decreases with increasing depth due to ongoing reduction of nitrate.

3. Reduced zone: nitrate-free zone due to complete reduced redox conditions

The redox conditions of the subsurface have been widely investigated using various approaches focusing on different redox-sensitive chemical compounds in groundwater such as nitrate, iron, sulfate, arsenic, uranium, and some organic contaminants. Modeling approaches have included (1) processbased approaches (e.g., Abbaspour et al., 2007; A. L. Hansen et al., 2014; B. Hansen, 2016; Lee et al., 2008), (2) geostatistical methods (e.g., kriging; Ernstsen et al., 2008; Goovaerts et al., 2005; Lin, 2008) and (3) machine learning (Close et al., 2016; Koch et al., 2019; Nolan et al., 2015; Ransom et al., 2017; Rosecrans et al., 2017; Tesoriero et al., 2015; Wilson et al., 2018). However, many of these approaches require large sets of data of especially groundwater chemistry, and it is costly and time-consuming to collect sufficient volumes of data. Furthermore, ancillary data to spatially extrapolate the water chemistry, for instance soil types, topography, land use, and surface slopes, only provide information about the nearsurface conditions (i.e., topsoil layer); therefore, predicting the redox conditions below the topsoil layer using these data may be inadequate. Particularly under geologically heterogeneous settings such as glacial terrain, the redox architecture can be complex (e.g., Hansen et al., 2021; Kim et al., 2019), with many shifts in redox state with depth at the same location. Upscaling of the point-scale measurements of redox conditions into the 3D space would benefit from more detailed spatial information of the subsurface geological architecture.

In Denmark, the uppermost 100 to $200 \mathrm{~m}$ of the subsurface generally consist of unconsolidated sediments reworked or deposited by glacial processes, making the subsurface architecture complex (Høyer et al., 2015; Jørgensen et al., 2015). Through the National Groundwater Mapping Program, Denmark is extensively covered with airborne electro- magnetic measurements (AEM) (Møller et al., 2009; Thomsen et al., 2004), and together with borehole data, 3D geological mapping of Denmark has predominantly been carried out as cognitive modeling (see, e.g., Høyer et al., 2015). In cognitive modeling, an experienced geologist combines all available subsurface data (e.g., boreholes, electromagnetic data, and seismic data) with preexisting geological background knowledge and performs interpretations through either manual (e.g., Jørgensen et al., 2013) or semi-automatic approaches (e.g., Gulbrandsen et al., 2017; Jørgensen et al., 2015). Complex geological settings, however, pose a challenge for 3D modeling, and interpretations between geological point data may lead to large uncertainties (Wellmann and Caumon, 2018).

The subsurface information itself contains uncertainties from sources that include measurement errors (Malinverno and Briggs, 2004), errors from using approximate physics (T. M. Hansen et al., 2014; Madsen and Hansen, 2018), bias from interpolation methods (Wellmann and Caumon, 2018), and processing errors when handling geophysical data (Claerbout and Abma, 1992; Madsen et al., 2018; Viezzoli et al., 2013). Even geological knowledge cannot be considered uncertainty free (Bond, 2015; Lindsay et al., 2012; Sandersen, 2008; Wellmann et al., 2018; Wilson et al., 2019) and may rely on the training and experience of the interpreter (Alcalde et al., 2017). These subjective biases are seen by some as one of the weak points of cognitive geological modeling (Bond, 2015; Wycisk et al., 2009) but are also argued to not imply a lack of scientific rigor (Curtis, 2012). It is difficult to fully incorporate the various uncertainties related to the subsurface information into cognitive modeling and even more difficult to propagate these uncertainties through to subsequent analysis such as hydrological modeling.

In recent years, some studies have adopted geostatistical simulation methods for geological mapping of the substratum in order to quantify and possibly account for some of these uncertainties. A few examples exist of multiple-point geostatistical (MPS) simulation utilized for mapping 3D geology with AEM data (Barfod et al., 2018; X. L. He et al., 2014; Høyer et al., 2017; Jørgensen et al., 2015; Vilhelmsen et al., 2019). However, AEM data provide structural information on the deeper subsurface (100-200 m) at a coarser resolution (Sørensen and Auken, 2004) and hence may not be adequate for providing structural information for simulations of $\mathrm{N}$ transport at catchment level occurring mainly within the upper $30 \mathrm{~m}$. A newly developed towed transient electromagnetic method (tTEM) (Auken et al., 2019) provides data at much higher resolution but with a lower penetration depth than AEM. tTEM is, therefore, ideal for high-resolution mapping when focusing on the uppermost 50 to $70 \mathrm{~m}$ of the subsurface. None of the previous studies has investigated the geological and redox architecture simultaneously, although these two are related and sometimes coevolved (Grenthe et al., 1992; B. Hansen et al., 2016; Wilkin et al., 1996; Yan et al., 2016). 
The development of redox zones in the subsurface is dependent on several factors, including (1) infiltration of atmospheric oxygen in geologic time; (2) anthropogenic leaching of nitrate; (3) the amount and reactivity of geogenic-reducing minerals such as pyrite or organic matter; and (4) the hydrogeological flow conditions. We propose a novel way to combine the available information on hydrogeology and redox conditions (boreholes, electromagnetic data, geological maps and digital elevation maps) by estimating a quantified uncertainty at unsampled locations in modeling using geostatistical simulation. We specifically use MPS to describe the spatial uncertainty in our models through a series of realizations of the subsurface that describe a quantified posterior distribution (Mariethoz and Caers, 2015). Using a bivariate training image (TI) of both geology and redox, we jointly simulate both redox and geology to ensure these will be consistent in the realizations. TIs are created using expert knowledge combined with the available data to directly incorporate prior expert geological information. In addition to our proposed efforts to combine redox and geology modeling, we have also utilized data and geological knowledge to subdivide the simulation volume into smaller volumes based on different geological characteristics and the depositional environment. We refer to such smaller volumes as "geological elements" (e.g., He et al., 2015; Høyer et al., 2015). Individual TIs are created with cognitive voxel modeling for each geological element such that they can be simulated independently and subsequently stitched together. Geological interpretation of the depositional environment and the age of the sediments will help create an event chronology that supports the independence of the individual geological elements.

The aim of this paper is to demonstrate and review the proposed methodology of jointly simulating and determining the distribution of redox and geology using MPS. This is, to our knowledge, the first study of simultaneous modeling of geology and redox architectures in a geostatistical high-resolution 3D model. The novelty of this paper is hence the presentation of the complete practical framework and steps needed to apply MPS for redox and geology modeling. These steps include quantifying spatial variability in TIs, quantifying conditional information and accounting for major geological depositional events via geological elements. This may be fundamental to better understanding $\mathrm{N}$ retention within the subsurface and important for future more targeted $\mathrm{N}$ regulation and management of agriculture for protection of vulnerable surface waters and groundwater, thus providing stakeholders with a powerful tool based on integrated expert knowledge and quantified estimates of structural uncertainty through probabilistic predictions of the complex interplay between redox and geological architecture.

\section{The study area}

The study area is a small Danish agricultural first-order hydrological catchment to Horndrup Bæk called LOOP3 with an area of approximately 550 ha. The area is located at the Jutland peninsula in Denmark, with a coastal temperate climate (Fig. 1). The dominant soil types are classified as sandmixed clay $(70 \%)$ and clay sand $(24 \%)$. Forest accounts for $18 \%$ of the catchment area, the rest being used for agricultural purposes except for a limited area taken up by buildings and roads. The catchment has been part of the Danish National Environmental Monitoring Program since 1989 aiming at evaluating the effect of the Danish $\mathrm{N}$ regulation of agriculture on the aquatic environment (Hansen et al., 2019). During the last almost 30 years, the $\mathrm{N}$ concentrations in soil water, drainage, shallow groundwater and streams have been measured regularly at several stations in the agricultural fields (Blicher-Mathiesen et al., 2019). Therefore, the site is ideal for testing new subsurface mapping techniques of geological and redox architectures.

The study area is located in a hilly glaciated landscape in the eastern part of Jutland just east of the highest point in Denmark (Fig. 1). The highest elevations reach $170 \mathrm{~m}$ above sea level (m a.s.1.) in the southwestern part and slope down to around $40 \mathrm{ma}$ a.s.1. in the northeast (Fig. 1a). To the north of the study area, a system of open tunnel valleys forms a low-lying area with several lakes. The catchment is dominated by glacial till deposits from the latest glaciation, and the orientation of the hills generally shows former ice push directions from the northeast. In the lowest parts of the terrain, occurrences of meltwater sand are also found. Occurrences of postglacial freshwater deposits can be found locally in smaller topographical lows (Jakobsen and Tougaard, 2020). Several buried valleys have been mapped outside the study area (Sandersen and Jørgensen, 2016; Buried Valleys, 2020; Sandersen et al. 2009; Fig. 1). The buried valleys were formed as elongated tunnel valleys underneath the ice sheets: they are generally between 1 and $2 \mathrm{~km}$ wide, and some of them have depths of more than $100 \mathrm{~m}$ (Jørgensen and Sandersen, 2006; Sandersen and Jørgensen, 2017). These valleys are generally filled with younger Quaternary sediments. In this region, the valleys mostly have two preferred orientations, one around WNW-ESE/NW-SE and the other around SWNE/WSW-ENE (Fig. 1), with the first mentioned clearly visible in the present-day topography.

\section{Materials}

Some data are specifically gathered for this study (tTEM and new boreholes; see Fig. 1), while other existing data are freely available through the Danish borehole database "Jupiter" (Hansen and Pjetursson, 2011) and the Danish geophysical database for onshore data "GERDA" (Møller et al., 

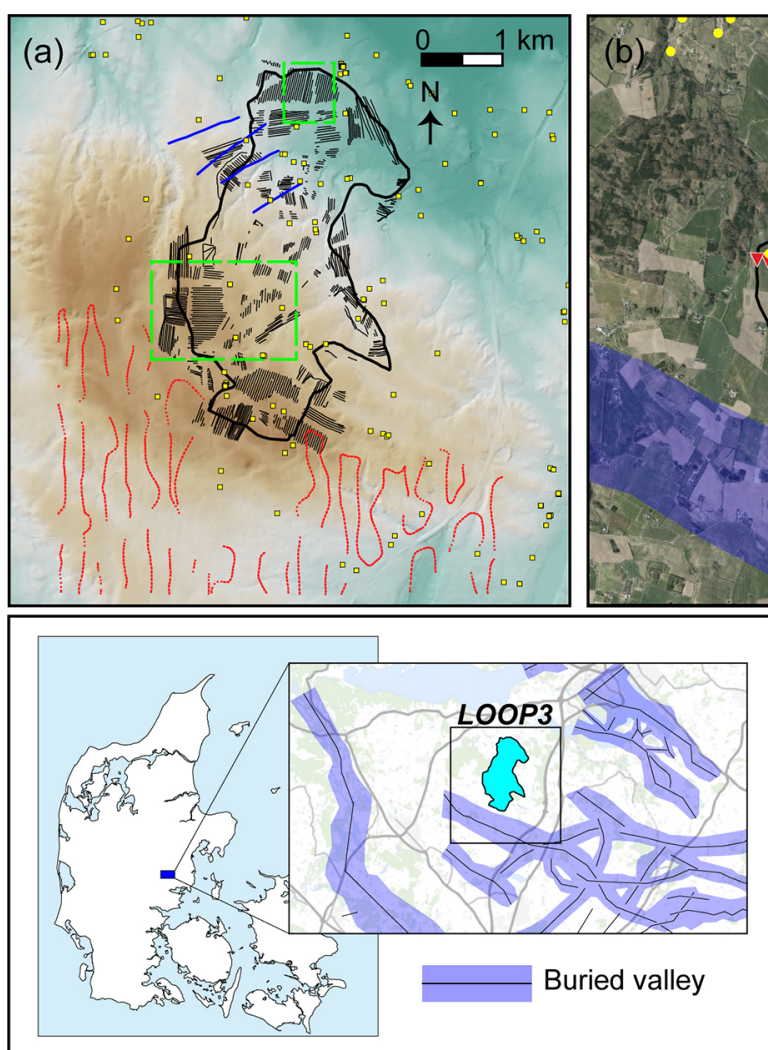

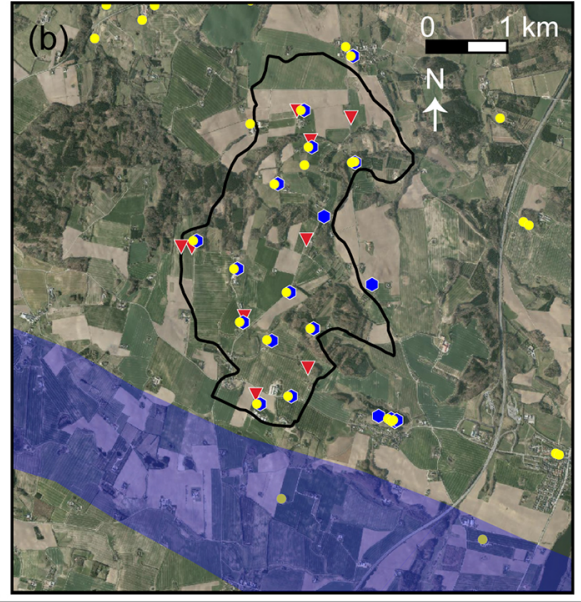

Elevation (m) (a) Structural data
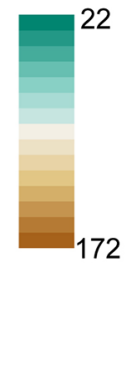

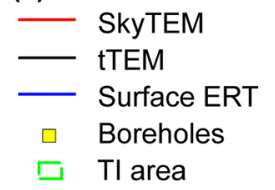

(b) Geochemical data

- Water chemistry (Existing) Sediment color (Existing)

v Water and sediment (this study) Buried valley

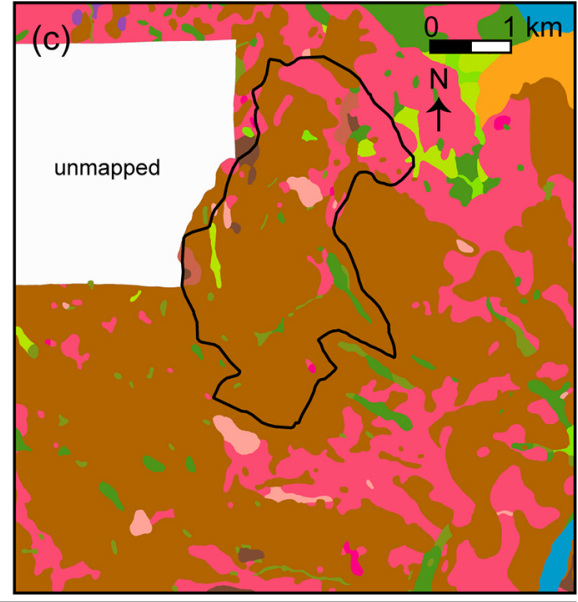

(c) Surface geology

Postglacial sand Postglacial clay

Postglacial gytta Postglacial peat Meltwater sand (Young)

Glaciolacustrine clay Meltwater gravel Meltwater sand (Old)

Meltwater clay

Gravelly till

Sandy till Clayey till Lake

Figure 1. The study area and available data, where (a) displays a digital terrain model, geophysical data and outlined TI areas, (b) an orthophoto (from Geodatastyrelsen, ortophoto forår, WMS Service, March 2021) and geochemical data, and (c) a surface geology map (1 m below surface, Jakobsen and Tougaard, 2020). Insets with a map of Denmark and regional view of the study site with mapped buried valleys (Buried Valleys, 2020).

2009). All available data are shown in Fig. 1 along with the terrain and outline of the study area.

\subsection{Geological and topographical data}

The digital elevation map presented in Fig. 1a is available from Styrelsen for Dataforsyning og Effektivisering (2016). The elevation map is resampled on a $25 \mathrm{~m} \times 25 \mathrm{~m}$ grid such that adjustment with interpreted surfaces is seamless. The geological surface map (Fig. 1c) of the surficial cover of Denmark is compiled from small pristine sediment samples collected at ca. $1 \mathrm{~m}$ depth using a so-called spear auger. The mapping geologists interpret the origin and type of the sediment in the field and classify a sediment type following the current terminology described by Jakobsen and Tougaard (2020). Samples are taken with a distance of $100-200 \mathrm{~m}$ to map the transitions between the different sediment types. Afterwards the surface geology symbols are transferred to a master map, contoured and color-coded, resulting in a geological map sheet on a scale of $1: 25000$ with a resolution of $\pm 100 \mathrm{~m}$ (Fig. 1c, GEUS, 2020).

Borehole lithological information (Fig. 1a) is gathered from the Jupiter database to which lithological sample de- scriptions have been reported since 1912. The borehole lithological samples are described and interpreted by geologists following standards outlined by Gravesen and Fredericia (1984), including interpretation of depositional environment and chronostratigraphy and thereby resulting in sediment types similar to those used in the geological mapping.

In our study site, a total of 18 specific sediment types are found in borehole descriptions and on the geological surface map combined. To lower the number of variables in the geostatistical modeling and potentially later on in hydrological simulations, the sediment types are grouped into five categories focusing on their hydrological properties and depositional environment (Table 1). For instance, the two till groups have vastly different hydrological properties because of the overall grain size difference between clay tills and sand/gravelly tills. The partly organic postglacial sediments may show variable hydrological properties. However, they are hugely important in terms of redox potential because of organic content; therefore, they are categorized into one group. 
Table 1. Lithology groups in the study area used in the geostatistical simulation. The sediment-type abbreviations in the right column represent the Danish sediment characterization standards.

\begin{tabular}{|c|c|c|}
\hline \multicolumn{2}{|c|}{ Lithology groups - study area } & \multirow[b]{2}{*}{ Sediment type } \\
\hline no. & Group name & \\
\hline 1 & Clay till & ML, (L) \\
\hline 2 & Meltwater sand/gravel & DS, DS-DG, DG, G, S, TS, (O) \\
\hline 3 & Meltwater clay/silt & DL, DI, DV, (FL) \\
\hline 4 & Sandy till & $\mathrm{MS}, \mathrm{MG}$ \\
\hline 5 & Postglacial (partly org.) & FP, FT, FS \\
\hline
\end{tabular}

\subsection{Geophysical data}

The tTEM (ground-based) and SkyTEM (airborne) are transient electromagnetic systems used for mapping subsurface resistivity variations (Auken et al., 2019; Auken and Sørensen, 2004). The SkyTEM system carries the instrument, transmitter loop and receiver coil in a sling load under a helicopter and is designed to map resistivity to several hundred meters in depth. The tTEM system applies the transient electromagnetic method in an offset-loop configuration which for the present study is configured using a $2 \mathrm{~m}$ by $4 \mathrm{~m}$ transmitter loop and a receiver coil at a distance of $9 \mathrm{~m}$, towed by an all-terrain vehicle (Auken et al., 2019). The tTEM system is designed to resolve resistivity from $2-3 \mathrm{~m}$ depth to ca. $70 \mathrm{~m}$ depth. Processing and inversion of tTEM data follow in general the scheme for SkyTEM, described by Auken et al. (2009). The inversion of the data is based on local 1D forward responses and spatial constraints between the model parameter forming a pseudo 3D model space (Auken et al., 2015; Viezzoli et al., 2008).

The tTEM dataset was collected in 2018. Although the coverage is rather patchy $(<50 \%$ of the model area in Fig. 1a), it provides valuable information on the geological setting. The final tTEM information used in the geostatistical modeling is the pseudo 3D model space moved to the closest grid node. Together with borehole lithological logs, tTEM represents the basis for modeling the geology. A few deep boreholes are used for the correlation between resistivities and lithologies.

Although located outside the study area, the SkyTEM data (Fig. 1a) add valuable information on the geological connections to neighboring areas. A small survey of surface electrical resistivity tomography (ERT) (e.g., Loke et al., 2013) gathered from the GERDA database supplements the tTEM survey in the northern part of the study area.

\subsection{Geochemical data}

Redox conditions can be defined both by sediment colors and concentrations of redox-sensitive elements such as dissolved oxygen, nitrate, iron, and sulfate in water (Ernstsen and von Platen, 2014; B. Hansen et al., 2016, 2021; Kim et al.,
2019 ) and the sediment fraction of ferrous iron $\left(\mathrm{Fe}_{\mathrm{FA}}^{\mathrm{II}}\right)$ of the formic-acid-extractable $\mathrm{Fe}\left(\mathrm{Fe}_{\mathrm{FA}}^{\mathrm{II}}+\mathrm{Fe}_{\mathrm{FA}}^{\mathrm{III}}\right)$ (Hansen et al., 2021). In this study, the sediment color was the primary indicator for defining redox conditions, and the water chemistry was used to supplement the sediment color interpretations. The sediment colors may be the result of the cumulative effects of the redox structure evolution since the deglaciation, while the water chemistry may display a snapshot of the short-term redox chemistry, which may be temporally variable. Therefore, we postulate that the redox conditions interpreted from the sediment colors may be more coherent with the geological structure than that of the water chemistry. In addition, the sediment colors provide 1D profile information of the redox conditions, and more data points are available compared to water chemistry which provide point-scale information. The sediment color and water chemistry data were extracted from the Jupiter database and the nine new boreholes that were drilled in this study (Fig. 1b).

Based on the sediment colors, oxic conditions are defined by red, orange, yellow and combinations of these colors. Gray, olive and blue colors represent reduced conditions. Mixed colors between oxic and reduced colors (e.g., yellowish gray) are defined as N-reducing conditions. Within the catchment boundary, the sediment color data were available at 14 boreholes in the Jupiter database and for the 9 new boreholes. Based on water chemistry, oxic is defined by dissolved oxygen greater than $1 \mathrm{mgL}^{-1}$, N-reducing is dissolved oxygen less than $1 \mathrm{mgL}^{-1}$ and nitrate greater than $1 \mathrm{mgL}^{-1}$, and both dissolved oxygen and nitrate below $1 \mathrm{mgL}^{-1}$ and iron greater than $0.2 \mathrm{mg} \mathrm{L}^{-1}$ are reduced (Hansen et al., 2021). Based on sediment chemistry, the fraction of Fe $\mathrm{FA}_{\mathrm{II}}^{\mathrm{II}}$ over $\mathrm{Fe}_{\mathrm{FA}}^{\mathrm{II}}+\mathrm{Fe}_{\mathrm{FA}}^{\mathrm{III}}$ is close to 0 in oxic conditions and close to 1 fraction in reduced conditions (Hansen et al., 2021). The values in between are interpreted as $\mathrm{N}$-reducing conditions (Hansen et al., 2021). The water and sediment chemistry data were available at 22 and 9 locations, respectively (13 in the Jupiter database and 9 in this study; see Fig. 1b).

\section{Methods}

\subsection{MPS modeling}

In this paper, we adopt a MPS simulation approach for quantifying the spatial uncertainty of the subsurface. Geostatistical simulation generally provides a way of quantifying the spatial uncertainty through different possible realizations of the subsurface architecture. These realizations are generated using stochastic modeling that accounts for the spatial dependency between the model parameters. We choose MPS simulation over, e.g., a two-point geostatistical approach because it is generally more capable of producing realizations with geological realism in terms of correlation and coherency of geological features (Journel and Zhang, 2006; Madsen et al., 2021; Mariethoz and Caers, 2015). Effectively reproducing 
coherent layers is key for successful subsequent hydrological modeling. The expected subsurface variability is portrayed in one or more TIs. MPS simulation is then able to utilize these TIs to generate different realizations of the portrayed subsurface through a stochastic sampling process. In total, these realizations, stemming from the MPS algorithm plus TI, together represent the quantified prior information of the system. In our case, the intuitive aspect of a TI, as opposed to a mathematical prior, is helpful for collaboration between mapping experts and geostatisticians.

Many MPS algorithms exist today (Gravey and Mariethoz, 2020; Guardiano and Srivastava, 1993; T. M. Hansen et al., 2016; Hoffimann et al., 2017; Mariethoz et al., 2010; Straubhaar et al., 2011; Strebelle, 2002; Tahmasebi et al., 2012). In the current study we use direct sampling (Mariethoz et al., 2010) as implemented in the DeeSse software package (Straubhaar, 2019). The main reason is its ability to utilize a bivariate training image that allows for joint simulation of geology and redox.

Simulations can be forced to match observational data, creating conditional realizations (Chilès and Delfiner, 2012; Journel and Huijbregts, 1978). Additional data not portrayed in the TI enter the simulation setup as either hard or soft data. Hard data correspond to information not allowed to change between different realizations and are placed directly in the simulation grid. Information from some boreholes can often be considered hard data because it is fixed in space and can have a relatively high resolution and accuracy. Hard data, in most cases, offer the first conditioning nodes and patterns to be matched during simulation, depending of course on the number of conditional points used. Consequently, hard data usually play a significant role in lowering the entropy of the final simulations. If data are not reliable enough (too uncertain) to be deemed hard data, they can instead be treated as uncertain information (soft data), quantified through probability distributions. In DeeSse, soft data probabilities are handled by introducing a penalty proportional to the soft data probabilities, such that it becomes difficult to find a match for a given lithology group or redox condition if the probability is low and conversely easier if the probability is high (Mariethoz et al., 2015).

\subsection{Ensemble statistics}

We introduce the mode and entropy as summary statistics for the ensemble of possible models of the subsurface. For a discrete probability distribution, the mode represents the most probable category in each voxel. The entropy, $H$, of a discrete probability distribution with $K$ outcomes is explicitly calculated as (Shannon, 1948)

$H=-\sum_{k=1}^{K} \log _{K}(p(k)) p(k)$,

where $p(k)$ is the probability of the $k$ th outcome. In our case, the entropy is calculated in each voxel where $p(k)$ is the number of times a certain category appears in the realizations divided by the number of realizations. The entropy reveals insights into the variability and hence the certainty of a specific outcome of each voxel. For $H=0$ we have full certainty (maximum information content) of the voxel category and conversely for $H=1$ (Hansen, 2021). The mode and entropy are hence comparable to the mean and variance in Gaussian statistics.

\section{Modeling setup}

In the following, we present the methodology progressing through the modeling workflow of the study area. The workflow consists of three phases: (1) preparing input data, (2) data analysis and setup including delineation of geological elements, construction of training images, preparing hard and soft data as well as setting up the simulation grid, and (3) running the MPS algorithm. A schematic overview of the workflow is seen in Fig. 2. The following sections primarily describe phase 2 .

\subsection{Simulation grid}

The simulation grid is discretized with a voxel resolution of $25 \mathrm{~m} \times 25 \mathrm{~m} \times 2 \mathrm{~m}$. The digital elevation model constitutes the top of the simulation grid, whereas both the bottom boundary and the internal subdivision into subvolumes are delineated by the geological elements (see below for details). The resulting simulation grid is shown in Fig. 3b, and the total number of voxels in the simulation grid is listed in Table 2.

\subsection{Geological elements}

The modeling domain is split into geological elements in order to subdivide the subsurface into separated volumes based on sediment heterogeneity and geological event chronology. In this way, smaller volumes with different lithologies and structures can be treated separately in the geostatistical simulations. The geologist interprets and delineates the geological elements of the subsurface using the geological, geophysical and topographical input data. Three distinct geological elements are identified in the study area; see Fig. 3a: (1) an upper Quaternary succession of sediments with an erosional boundary to the pre-Quaternary sediments below, (2) a large, deeply eroded, buried tunnel valley and (3) pre-Quaternary Paleogene clays defining the bottom of the groundwater system. The simulation grid is chosen to include only Geological Elements 1 and 2 (see Fig. 3b). The third geological element, the Paleogene clay, constitutes a thick non-penetrable layer, and as its top defines the lower hydrological boundary of the area, geostatistical simulation has not been performed on this geological element. We find it reasonable to do so because the Paleogene clays are homogeneous and very thick. This type of clay is generally found to be a good electrical conductor in Denmark, and because the TEM method is sensitive to 


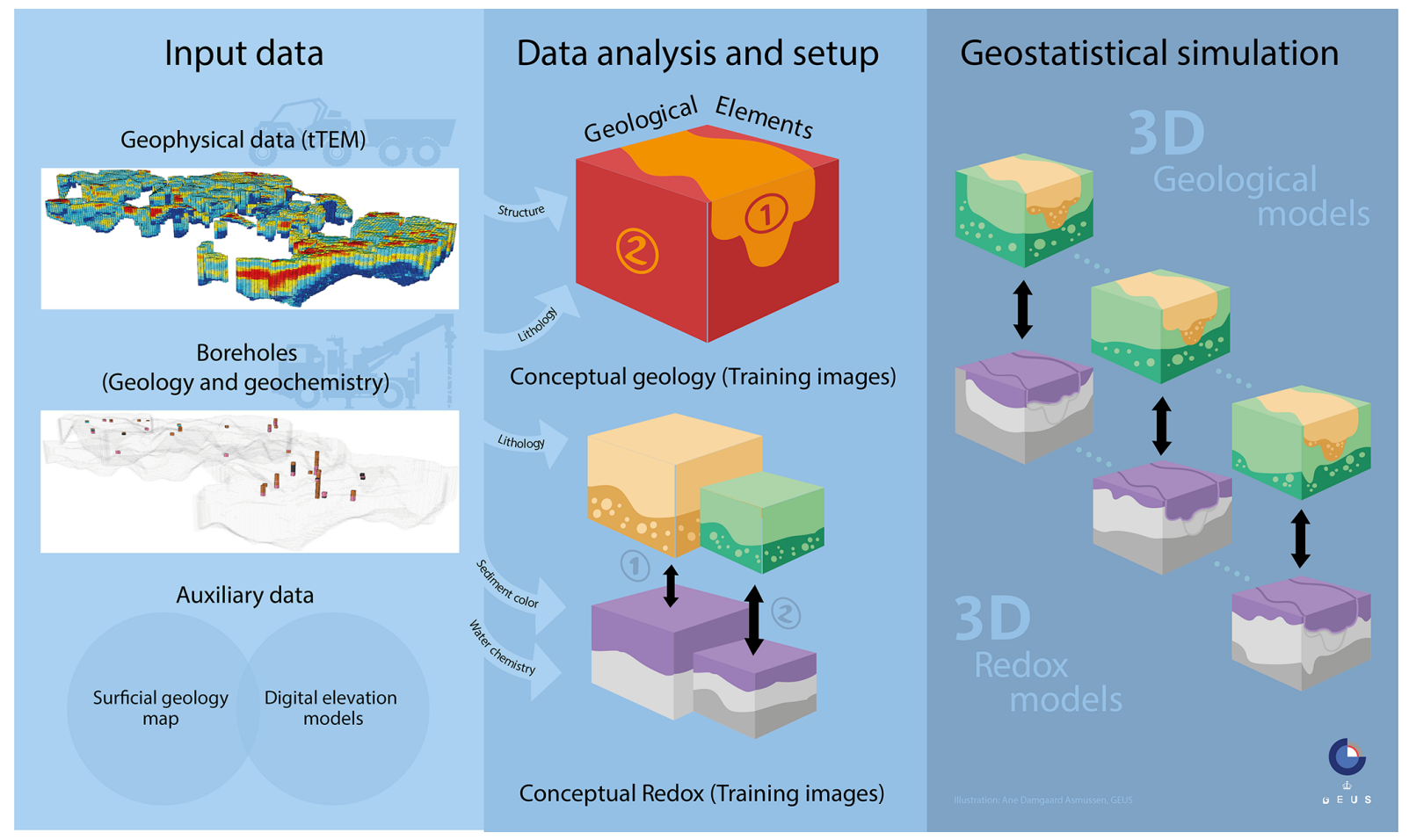

Figure 2. Schematic overview of the proposed workflow from input data (left) through data analysis and simulation setup (middle) and geostatistical simulation (right).

Table 2. Summary of the number of voxels for simulation grid and TIs. The relative sizes of the TIs are calculated as the ratio between the number of voxels in the TI and the number of grid voxels.

\begin{tabular}{llll}
\hline & Number of voxels & Number of voxels in TI & Relative size of TI \\
\hline Quaternary sequence (Element 1) & 143698 voxels & 54258 voxels & $37.76 \%$ \\
Buried valley (Element 2) & 57015 voxels & 12449 voxels & $21.83 \%$ \\
Total & 200713 voxels & 66707 voxels & $33.24 \%$ \\
\hline
\end{tabular}

good conductors, the depth to the top of the layer can be determined with low uncertainty (e.g., Danielsen et al., 2003). Delineation of the Paleogene clay surface from the tTEM data is therefore straightforward as long as it can be found within the depth of investigation of the tTEM method (Vest Christiansen and Auken, 2012). Furthermore, in the study of Barfod et al. (2018), Paleogene clays were given a discrete value in the MPS simulation but showed only little variability in the spatial extent.

We assume independence between the two uppermost geological elements because they appear to represent different geological events. The buried valley to the north is apparently incised into both the Quaternary sequence and the pre-Quaternary clay below, and the infill is clearly different compared to the Quaternary sediments to the south. The buried valley (Geological Element 2) has a more complex infill, with individual layers of limited extent compared to the Quaternary layers of Geological Element 1, which show less complexity and more pronounced stratification more or less undeformed by the glaciations. The geological events that formed each element are therefore considered different, although they contain the same lithology groups, and this justifies the assumption of independence from a geological point of view. The buried valley to the north takes up roughly a quarter of all voxels, whereas the Quaternary sequence occupies the main part of the simulation grid (Table 2).

\subsection{Training images}

The TIs providing information about the geology and redox conditions within the geological elements are designed in a sequential workflow (Fig. 4a and b). At first, two geology TIs are generated, one within each of the two geological elements. The first step is to appoint a smaller part of the simulation area for detailed geological characterization and interpretation using a voxel modeling approach; see Fig. 4a. The lithological population of the voxels is based on the conceptual understanding of the geological event chronol- 

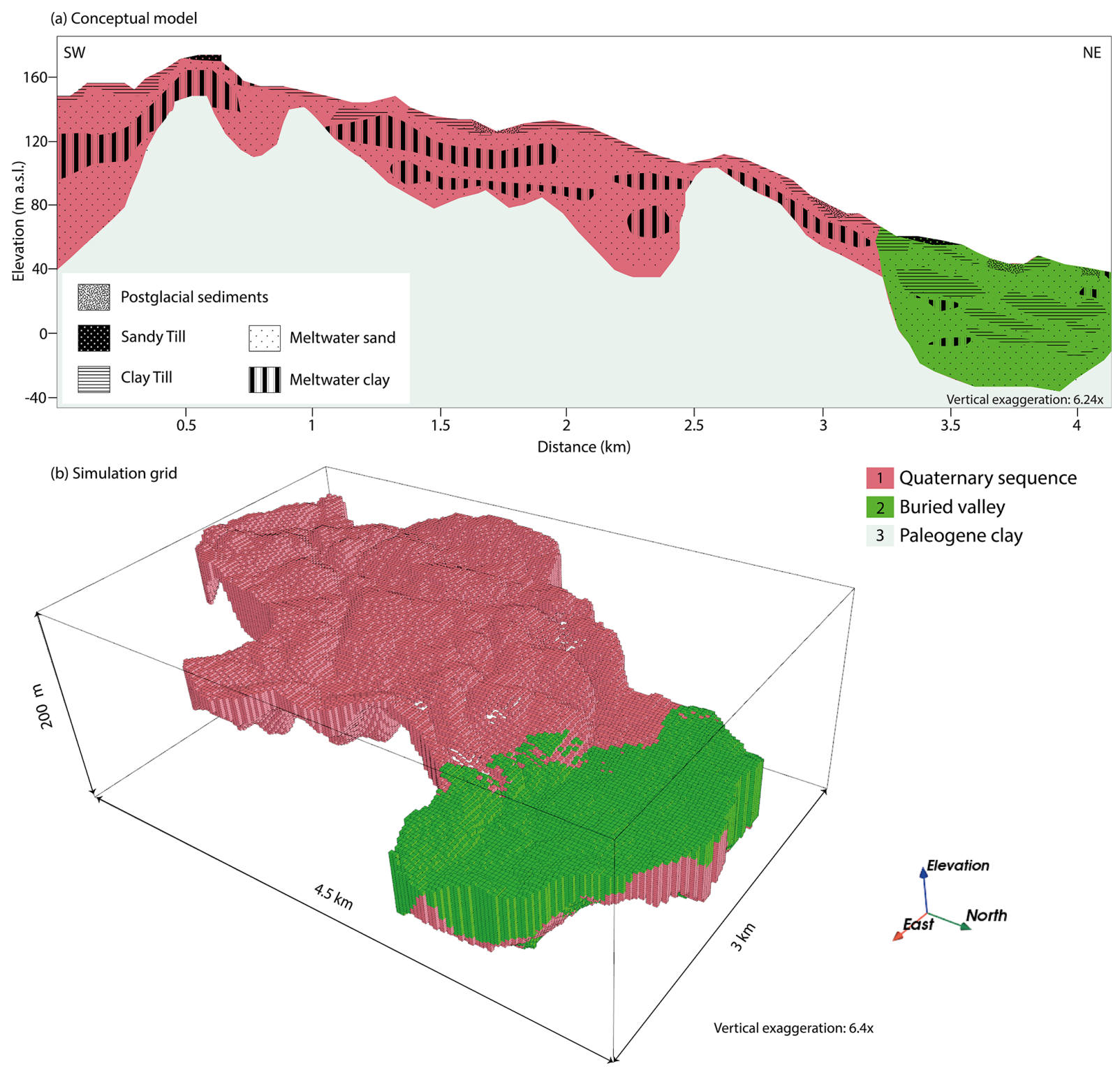

Figure 3. (a) Conceptual drawing of the SW/NE profile through the study area. (b) Simulation grid showing the two main geological elements used for the geostatistical simulation.

ogy, glacial processes forming the area, and an interpretation combining borehole information, digital elevation maps, surface geology maps and the spatially distributed geophysics using regional geological understanding. The criteria for TI area selection in this specific study were dense data coverage of geophysics and especially the availability of boreholes that penetrate the entire modeling domain with goodquality lithological descriptions. For despite having a better geophysical data coverage in the southernmost part of study area according to Fig. 1a, the TI in the Quaternary element is chosen based on sufficient geophysical data coverage and having the two main boreholes within its borders. The TI section needs also to represent the expected variability in geol- ogy, in both vertical and horizontal extents, which is another selection criterion. In reality, it is not possible to capture the total variability and heterogeneity in the TI, due to its finite size, but the important features must be represented. In TI1, smooth glaciotectonic deformation of the Quaternary units due to ice push from the northeast is modeled. Likewise, smaller incised buried valleys in the Eocene clay with mostly sandy infill are included based on the tTEM spatial data coverage; see Fig. 3a. TI2 represents the sedimentary infill in a large buried valley (geological element 2), where more regional information from nearby buried valleys of the same generation was also taken into account (see Fig. 1b). This information combined with the tTEM data coverage, two bore- 

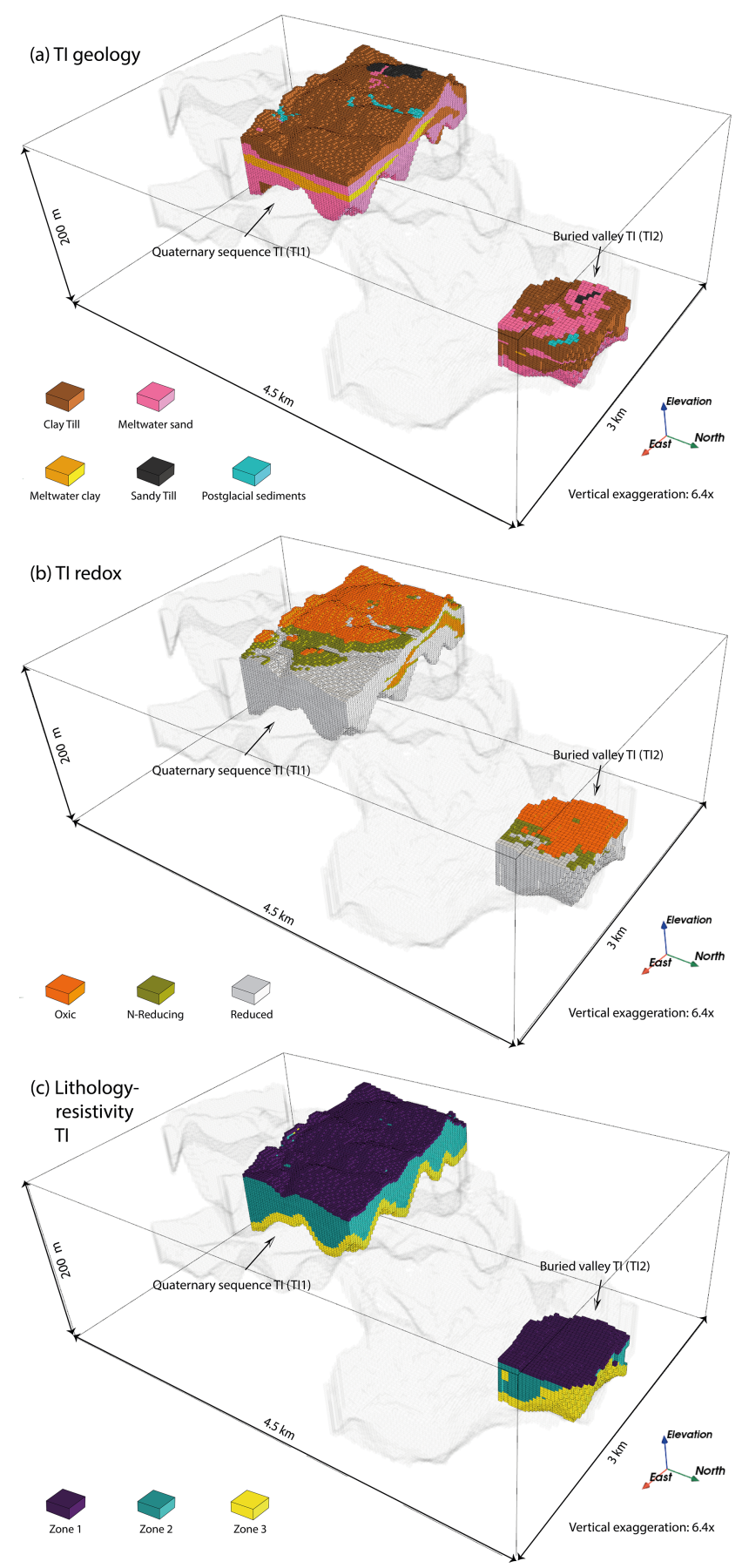

Figure 4. (a) Geology TIs overprinted on the simulation grid. (b) Redox TIs overprinted on the simulation grid. (c) Zones in TIs used for resistivity-lithology relationship inference.

holes within the valley north of the study area, and the surface geology maps has been the basis for the voxel modeling of TI2. The complexity in the infill of the buried valley is represented by individual layers of limited extent as seen in Fig. 3a.
The geological training images are then translated into redox TIs by upscaling the redox interpretations of the sediment colors and water chemistry as described in Sect. 3.3 (Figs. 4b and 5). The sediment color data were first discretized into a $1 \mathrm{~m}$ interval, and then the redox condition for each interval was assigned according to the sediment color. The interpreted data were summed up separately for sand and clay for each TI area to produce depth profiles of redox conditions (Fig. 5a, d, g and j). For the Quaternary sequence and buried valley TIs, 13 and 7 boreholes are available with sediment color descriptions (Fig. 5b, e, h and k), respectively, and 5 and 3 boreholes are available with water and sediment chemistry (Fig. 5c, f, i and l), respectively.

The redox interpretation revealed that in the Quaternary sequence, oxic conditions are much deeper in sand (at least $20 \mathrm{~m}$; Fig. 5a and c) than in clay (4-6 m; Fig. 5d and f). We postulated that the Quaternary sequence is the geological window type of redox architecture proposed by Kim et al. (2019): the sandy units exposed to the surface act as "geological windows", which allow transportation of oxidants (i.e., oxygen and nitrate) via gas and water into the deeper subsurface, resulting in development of a deep oxic zone below a reduced clay layer. In the Quaternary sequence area, all the boreholes for the water and sediment chemistry were collected in these geological windows, which are predominantly in oxic conditions, confirming our interpretations. In the buried valley, the oxic layer was relatively shallow compared to that of the Quaternary sequence. This shallower oxic layer may be attributed to a shallower and temporally invariant groundwater table in this area compared with the Quaternary sequence. A secondary oxic layer below the first oxic layer is not expected, due to the clay-dominant conditions of the surface geology (mainly clay till; Fig. 1c) and subsurface structure. We concluded that in the buried valley, oxidants are delivered either vertically via water infiltration or gas diffusion or the top oxic layer (4-6 $\mathrm{m}$ below the land surface) from the Quaternary sequence, resulting in the planar type of redox architecture (Kim et al., 2019).

Based on these interpretations, we assigned each lithology group with a probability of belonging to each of the three redox conditions at the surface (Table 3); $80 \%$ of the meltwater sand in the geological windows (sand units connected to the surface) of TI1 was assigned to be oxic down to $20 \mathrm{~m}$, and the rest was equally distributed between $\mathrm{N}$-reducing and reduced conditions, respectively, to allow variability in simulations. These $\mathrm{N}$-reducing and reduced conditions were mainly located at lower elevations because of the higher possibility of water-saturated conditions. For the connected sand, with increasing depth, the fraction of oxic voxels was assumed to be reduced by $10 \%$ compared to that of the overlying layer for the $20-30 \mathrm{~m}$ interval and by $20 \%$ for depth below $30 \mathrm{~m}$. The sand voxels that are not connected to the land surface were assumed to be reduced. The N-reducing conditions are always located at the boundary of oxic conditions in the profiles; the fraction was limited to $10 \%$ of the total sandy vox- 


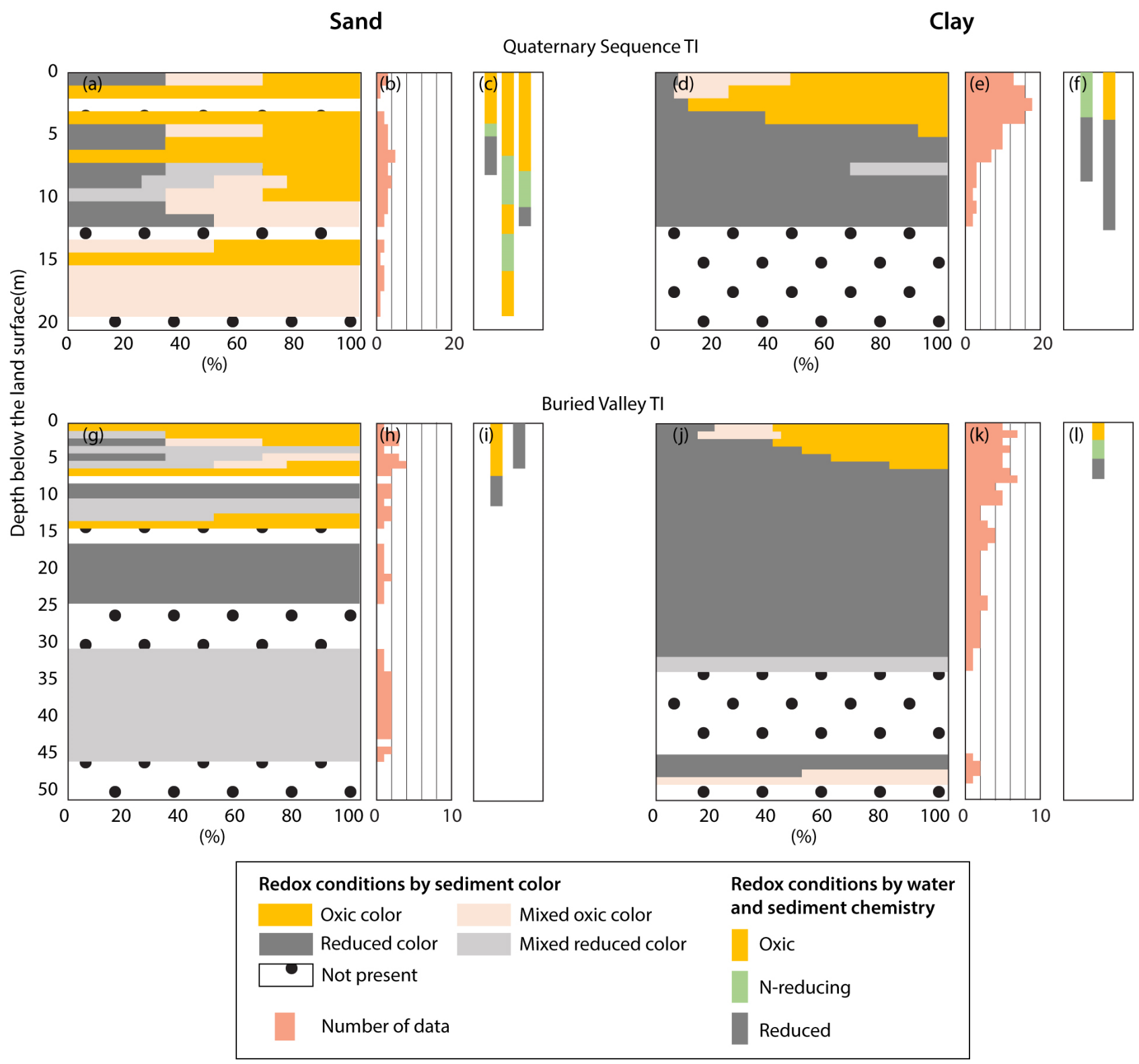

Figure 5. Profiles of redox conditions for sand and clay for each TI area based on geochemical observations. The redox interpretations based on the sediment colors are done separately for sand (a) and clay (d) of the Quaternary sequence TI and of the buried valley TI ( $g$ and $\mathbf{j}$, respectively), and the number of boreholes used in the interpretations are shown in (b), (e), (h), and (k), respectively. The number of boreholes of each redox color category (oxic, mixed oxic, mixed reduced and reduced colors) are normalized and shown in $\%$. The redox interpretations based on water and sediment chemistry of sand and clay of the Quaternary sequence and buried valley TIs are shown in (c), (f), (i), and (l), respectively.

els of each layer in the TIs. The rest was assigned to reduced conditions. For clay till and meltwater clay of TI1, 60\%, $20 \%$, and $20 \%$ of the first-layer voxels (Table 3 ) were attributed to oxic, $\mathrm{N}$-reducing, and reduced conditions in the order of elevation (lower elevation $=$ reduced condition) due to proximity to streams. With increasing depth, the fractions of $\mathrm{N}$-reducing and reduced conditions were assumed to be increased by $10 \%$ and $20 \%$, respectively, up to $6 \mathrm{~m}$ below the land surface. Below $6 \mathrm{~m}$, clay was always reduced.

For meltwater sand and sandy till of TI2, $80 \%, 10 \%$, and $10 \%$ of the top layer (Table 3 ) were attributed to oxic, $\mathrm{N}-$ reducing, and reduced conditions in the order of elevation. Below the first layer, the fractions of the oxic and N-reducing voxels then were assumed to be decreased by $70 \%$ and $50 \%$, respectively, and the rest was assigned to reduced conditions. 
Table 3. The probabilities for redox conditions (oxic, N-reducing and reduced) based on geochemical observations in Fig. 5 for the top (surface) layer of the training images. The probabilities for each lithology group sum to one.

\begin{tabular}{lrrr}
\hline Lithology group & Oxic & N-reducing & Reduced \\
\hline Clay till & 0.6 & 0.2 & 0.2 \\
Meltwater sand/gravel & 0.8 & 0.1 & 0.1 \\
Meltwater clay/silt & 0.6 & 0.2 & 0.2 \\
Sandy till & 0.8 & 0.1 & 0.1 \\
Postglacial & 0.05 & 0.05 & 0.9 \\
\hline
\end{tabular}

Clay till and meltwater clay of the buried valley TI, $60 \%$, $20 \%$, and $20 \%$ of the top layer (Table 3) were attributed to oxic, N-reducing, and reduced conditions in the order of elevation. The fractions of oxic and $\mathrm{N}$-reducing voxels were assumed to be lowered by $60 \%$ and $20 \%$, respectively, compared to those of the overlying layer with increasing depth. The rest was assigned reduced conditions.

Postglacial sediments, which are freshwater deposits often rich in organic material (Jakobsen and Tougaard, 2020), were assigned almost exclusively with reducing conditions (90\% probability). Like the sandy and clayey sediments, we distributed the remaining $10 \%$ probability equally among the other two redox conditions to allow for some variability.

The described sequential workflow of geology and redox TI construction ensures consistency between the two training images in the joint simulation of the two variables. Approximately one-fourth of 1 reaches outside of the study area, whereas the whole of TI2 is located within. We intentionally do this to ease the construction of TI1 as the surrounding area to the west shows similar geological variability to the Quaternary sequence and therefore provides helpful information during the creation of TI1. Additionally, this information is independent and allows more possible matching configurations in the TI during simulation. TI1 is about one-third of the size of the Quaternary sequence element, and that of TI2 is one-fifth of the buried valley element (Table 2). The TIs used in this study have different statistical properties depending on the location; i.e., they are non-stationary. For instance, visually it is easy to confirm that the probability of finding an oxic redox condition in the lower part of the TI is much different than in the top. A non-stationary TI is not unacceptable but can have some unwanted effects when combined with MPS algorithms expecting a stationary TI and will be discussed later.

\subsection{Conditioning data}

\subsubsection{Hard data}

The geological surface map and the borehole data (both lithology and redox) were treated as hard data in the simulation grid and are shown in Fig. 6.
The sediment types that were grouped into lithologies (Table 3) were placed at the top voxel in the simulation grid, corresponding to the surface. We do not explicitly use the entire geological map as hard data. The borders between the lithology polygons of the surface geology map were originally delineated based on sediment samples, geomorphology, and topography (Jakobsen and Tougaard, 2020). In general, it means that the closer you are to the center of a polygon, the more certain you are of the correct lithology. Conversely, the boundaries between polygons represent the least certain parts of the map. A buffer zone is therefore adapted between the polygons to express the uncertainty of the geological surface map. The buffer zone is simply created by checking all neighboring voxels for each voxel in the surface map. If the current voxel shares a value with all surrounding voxels, it is likely situated safely within a polygon and is kept as hard data. Conversely, if one of the neighboring voxels provides a mismatch, the current voxel is likely close to a polygon boundary and is not included as hard data. Alternatively, a negative buffer around each polygon could be adopted.

The redox conditions are grouped into the three main redox categories: oxic, $\mathrm{N}$-reducing, and reduced. The wells indicate that the area is dominated by reduced conditions. Oxic conditions are mainly present in the upper meters of the simulation domain, and only one well displays the reverse trend with an oxic part below reduced conditions due to heterogenous geology.

\subsubsection{Soft data}

We use the geological surface map (Fig. 1c) as a soft data indicator of lithology in the buffer zone. Geological complexity is one of the main drivers of uncertainty in geological mapping along with the amount, quality and spatial distribution of data (Keefer, 2007). Accessibility is an important factor to consider in terms of both amount and spatial distribution of data (Keaton and Degraff, 1996). In Denmark, however, neither terrain nor private property poses a major issue when mapping surface geology. On the level of investigation, the geology in the study area is relatively simple, alleviating some of the uncertainty due to complexity. The main source of uncertainty in the surface geology maps comes from interpretations of sediment types from the small samples and the final shape and size of polygons. We generally consider the surface geology to be very certain data and thus provide all values with 0.7 probability of being true. The last 0.3 probability is split equally between the four other lithologies, which reflect the uncertainty level of misinterpretations. Regardless, because much of the geological surface map is used directly as hard data, the quantified uncertainty only affects the buffer zone as outlined earlier. For the redox domain, we translate the geological surface map to soft redox data using the probabilities provided in Table 3 .

The tTEM 3D resistivities in the simulation grid contain 87547 voxels covering $43.5 \%$ of the simulation grid (Fig. 7). 

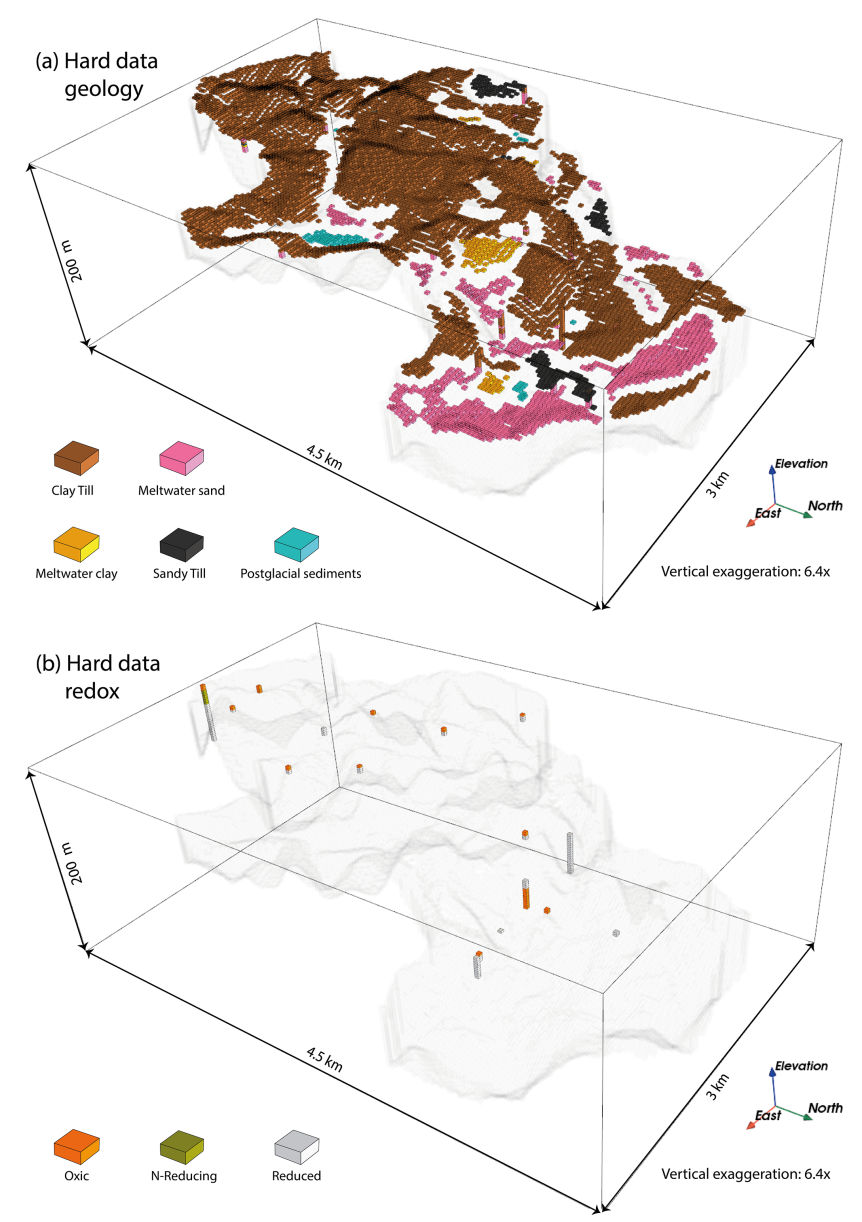

Figure 6. (a) The geology surface map along with the geology wells placed on the simulation grid as hard data. (b) The redox wells on the simulation grid as hard data.

The tTEM 3D resistivity grid is converted into soft data probabilities of geology. This requires a known lithologyresistivity relationship, which here is established in two parts.

Firstly, because the geological TIs are based on interpretations of resistivity data in combination with geological information, many voxels in the TIs have a corresponding resistivity value in the resistivity grid (Fig. 7). Local histograms for the study area are built for each lithological group by collecting all the resistivity values in the two geology TIs. We divide the TIs into three zones to account for some of the nonstationarity with depth that affects this relationship (Fig. 4c). The upper $4 \mathrm{~m}$ make up zone 1 and are the only place where we expect postglacial sediments and sandy till. Because both of these lithology classes contain so few counts in the TIs, they would otherwise be underrepresented in a relationship covering the entire TI. Zone 2 covers the bulk part of the TIs from $4 \mathrm{~m}$ below the surface and down to zone 3 covering the last $10 \mathrm{~m}$ of the TIs. Zone 3 contains very low resistivities from the underlying conductive Paleogene clay that are "smeared" into the resistivities of the above-lying material due to averaging during inversion (dark blue colors in Fig. 7). This smearing effect happens at large contrasts in the subsurface resistivity and generally increases with depth as the resolution of the data decreases (Vignoli et al., 2015). This affects the inference of the lithology-resistivity relationship by lowering the overall resistivity of meltwater sand/gravel that mainly constitutes the lower parts of the study area. By separating the last $10 \mathrm{~m}$ in a disconnected zone from the bulk zone, we minimize the effect of these low resistivities on the overall lithology-resistivity relationship in zone 2 . The final pooled histograms for the two TIs are shown in Fig. 8a-c for each of the respective zones. For all zones, relatively low resistivities are attributed to clay-rich deposits, whereas relatively high resistivities are attributed to sandy lithologies, although meltwater sand/gravel accounts for many of the lower resistivity counts in the zone 3 relationship due to the smearing effect. Generally, the resistivity of clay till is so high that it corresponds to much of the meltwater sand/gravel resistivities. Meltwater clay/silt is the most distinctive lithology group tending towards rather low resistivity values. The histograms confirm the common issue of lithologies overlapping in the resistivity domain (Barfod et al., 2016; Schamper et al., 2014). The histogram with the best separation is seen in zone 2 , which indicates the importance of detaching the low-resistive meltwater sand in zone 3 . The sandy till in zone 1 is associated with some of the highest resistivity values found in the TI area, whereas the postglacial sediments cover a large spectrum within the most ambiguous resistivity values. For each bin in a histogram, we summarize the size of each lithology group and stack them. If we then normalize with the total number of counts within that resistivity bin, we get a cumulative distribution of the lithologies (Fig. 8d-f).

Secondly, because there are very few counts for the low and high resistivities, here defined as $<0.5 \%$ of the total counts for each zone, we let an a priori established relationship govern these values. We assume that low resistivities are associated with clay till and meltwater clay/silt, whereas high resistivities are associated with sandy till and meltwater sand/gravel. This is based on our general understanding of the lithology-resistivity relationship in the area and supported by Barfod et al. (2016) and Schamper et al. (2014). The proportions between, e.g., the two low-resistive lithology groups are found by retrieving the proportion between clay till and meltwater clay/silt in the respective zone of the TIs (Fig. 4). For instance, there is no meltwater clay/silt in zone 1 of the TIs, and hence we expect that low resistivities will only be attributed to clay till (Fig. 8d), while meltwater clay/silt covers approximately $25 \%$ among the two lowresistive lithology groups in zone 2 (Fig. 8e). To smooth the transition between the relationship inferred from the TIs and the a priori distribution, we weight the adjacent 10 bins between the two relationships. The weights are distributed linearly such that below the cut-off of $0.5 \%$ only the a priori relationship is used and 10 bins from there the relationship relies solely on the inferred relationships from Fig. 8a-c. 


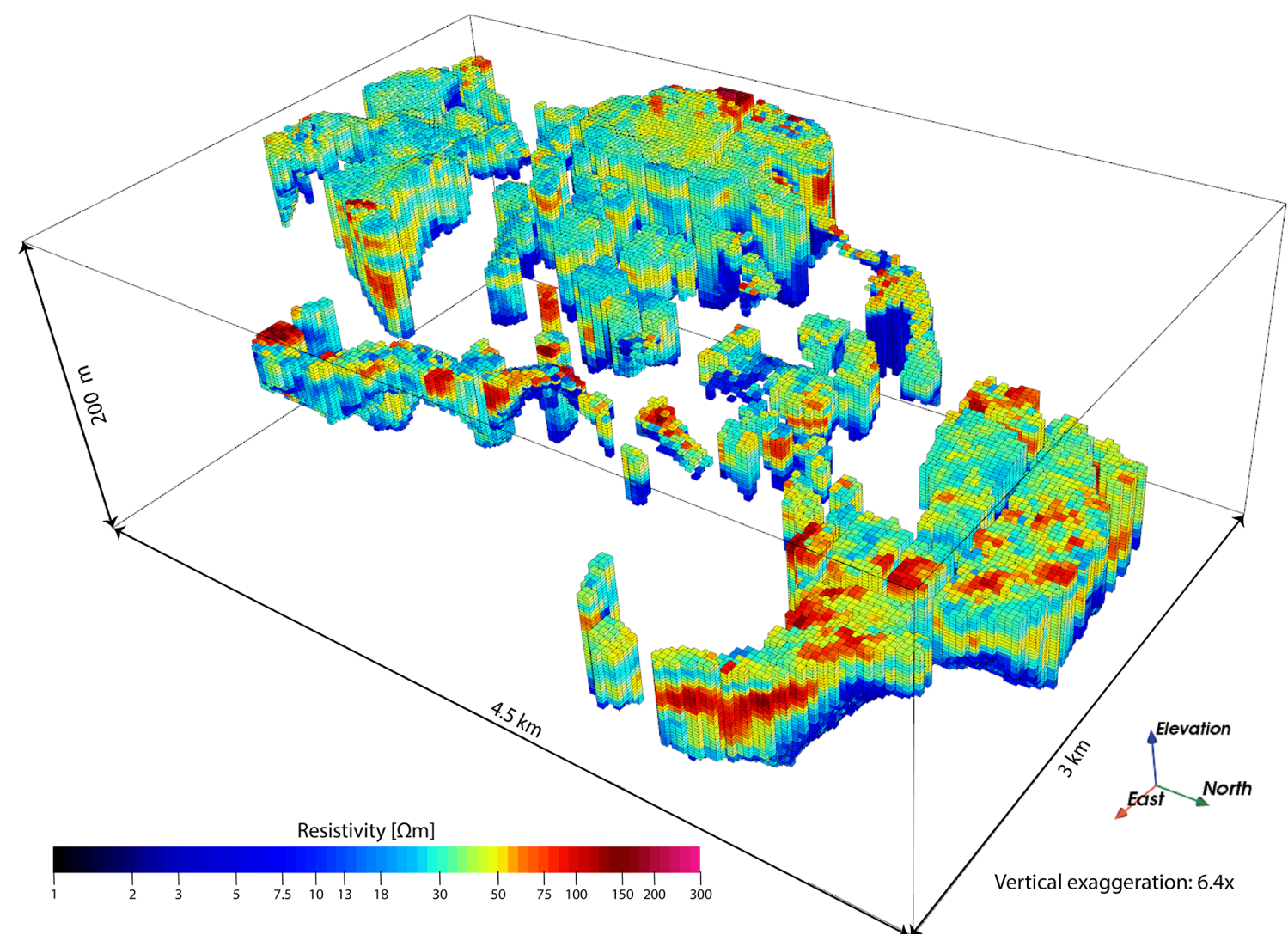

Figure 7. 3D resistivity grid from the tTEM model results in a grid equal to the simulation grid.

Regardless, the effect of the a priori relationship is minuscule, as in all zones approximately $95 \%$ of all resistivities in the simulation grid are supported solely or at least partially by the inferred relationship. The remaining $5 \%$ is supported solely by the a priori established relationship as seen in the total distribution of all resistivities in the simulation grid in Fig. $8 \mathrm{~g}-\mathrm{i}$.

Figure 9 presents the final soft data probabilities for each of the $k$ lithology classes $p_{\text {tot }}(k)$. In zones 2 and 3 (Fig. 9f) the inferred lithology-resistivity relationships from Fig. 8e and $\mathrm{f}$ are used to convert the resistivity grid from Fig. 7 to soft data probabilities $p_{\mathrm{tTEM}}(k)$. At the surface the soft data probabilities from the surface geology $p_{\mathrm{sg}}(k)$ are combined with probabilities from the resistivity data to obtain the final soft data probabilities $p_{\text {tot }}(k)$ :

$p_{\text {tot }}(k)=\frac{p_{\text {sg }}(k) p_{\text {tTEM }}(k)}{\sum_{k=1}^{K} p_{\text {sg }}(k) p_{\mathrm{tTEM}}(k)}$

for each of the $K=5$ lithologies. The stronger colors at the surface represent the overall certainty level of 0.7 from the surface geology discussed previously. The tTEM data are largely more ambiguous in guiding the soft data probabilities as evident from the resistivity-lithology relationship in Fig. 8 and are mostly within the color range of yellow and red in Fig. 9a-c. The dominance of the clay till and meltwa- ter sand/gravel (Fig. 9a and b) in the study area is apparent in the soft data probabilities when compared to, e.g., meltwater clay/silt, which is expected primarily in areas of lower resistivities. We do not expect much meltwater clay/silt at the boundary of the modeling domain as portrayed in the training images. The inferred relationship in zone 3 helps guide meltwater sand/silt to lower resistivities but may not affect the results more than the general uncertainty in the boundary estimate, which depends largely on the TTEM resolution. Due to the low count of sandy till and postglacial sediments (Fig. 9d-e) in the TIs, the probability for these lithology classes is considerably lower than the three main classes of the study area.

Based on these soft data probabilities, a mode and entropy are calculated and shown in Fig. 10. The entropy is generally low at the surface, where the soft information from the surface geological map is present. Similarly, the mode is dominated by the soft information from the surface geological map. Due to the overlapping relationship in the resistivity domain (Fig. 8), the soft data based on the tTEM data are not as informative at the surface and do not help to lower the entropy much further. In general the entropy of the tTEM data ranges between 0.8 (yellow color in Fig. 10b) and 0.3 (red color). In areas of particularly high resistivity the entropy drops even lower (black color), implying that the tTEM 

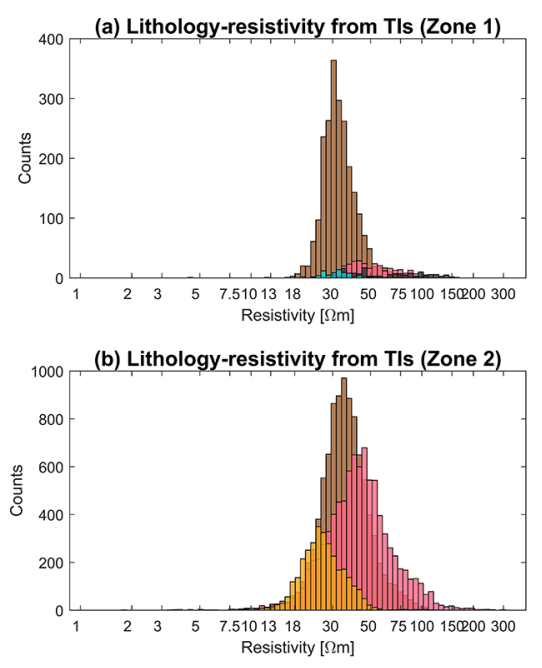

(c) Lithology-resistivity from TIs (Zone 3)

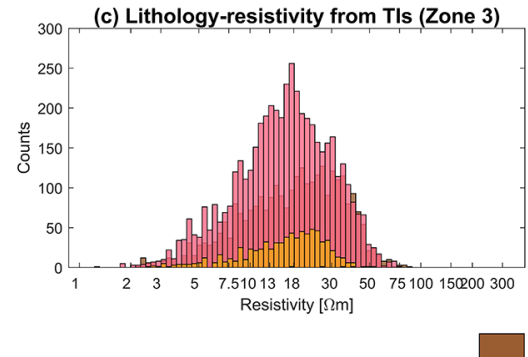

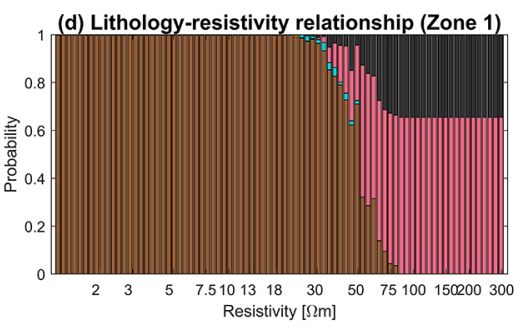
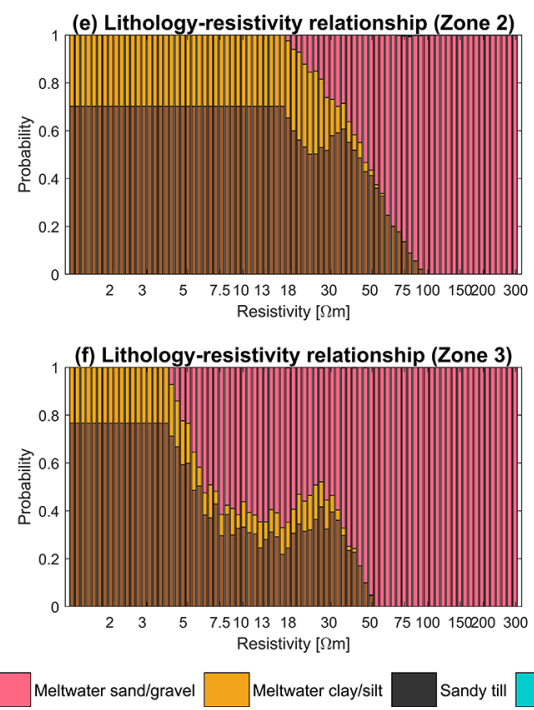

(g) Distribution of resistivities (Zone 1)

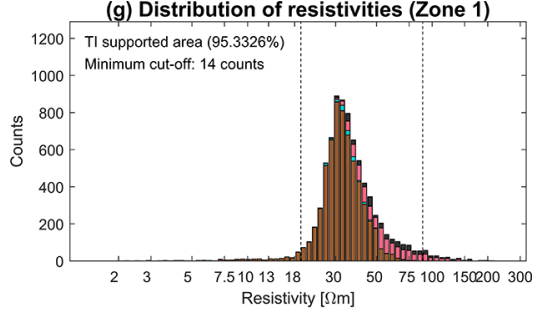

(h) Distribution of resistivities (Zone 2)
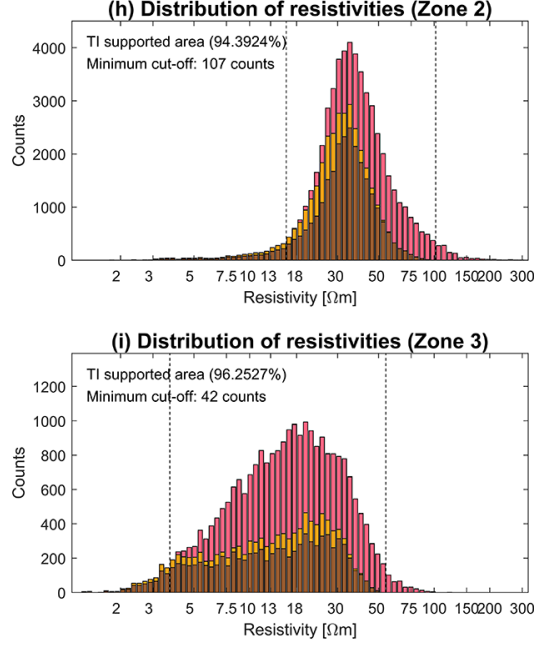

Figure 8. Resistivity-lithology relationships illustrated as (a-c) histograms of resistivity for each lithological group based on the training images (Fig. 4) and the corresponding values in the 3D resistivity grid (Fig. 7), (d-f) TI-based cumulative distribution for all lithological groups for each bin and a priori relationship for rare resistivities and (g-i) distribution of resistivity values in the corresponding zone in the simulation grid (Fig. 9f) overprinted with the lithology-resistivity relationship established in (d-f).

data provide high certainty on the lithology group. The overall pattern in the mode model (Fig. 10a) reveals a slight tendency to form coherent layers, especially seen in the buried valley. However, in many places the mode of the soft data is also rather patchy and changes between small clusters of either meltwater sand or clay till. These clusters simultaneously show high entropy (Fig. 10b), which implies a wide distribution of possible outcomes. Thus, these patchy structures can be consistent with information of more coherent layers.

If a single lithology group has a soft data probability greater than or equal to 0.5 , a small fraction of these soft data is converted into hard data. This makes sure that soft data are not underrepresented in MPS simulations, which is a recurring problem in MPS (e.g., Hansen et al., 2018). The conversion rates based on the soft data probabilities are shown in Table 4.

\subsection{Parameterization of the simulation algorithm}

In direct sampling, the nodes in the simulation grid are visited sequentially. The training image is consulted at each iteration to find a suitable candidate at each visited node based on already simulated (conditional) nodes. To specify how this procedure is performed, several fundamental parameters need to be set in direct sampling (Mariethoz et al., 2010).

- The number of conditional data to consider when searching the TI, which influences the variability. Here, a maximum of 20 neighboring nodes are used, preventing verbose copying from the TIs happening too often.

- The distance measure determining how well the candidate values match the conditional nodes in the simulation grid. Because both geology and redox are categorical variables, we use the number of mismatching nodes as a distance measure with a tolerance of $10 \%$ mismatch. For 20 neighboring nodes, we hence allow 2 conditional nodes to differ between the TI and the simulation grid to accept the currently proposed value.

- The maximum number of iterations allowed us to find a suitable match within the TI. Because the TIs in the current study are of a reasonable size, we allow a scan of the entire TI to find a suitable match. This alleviates some of the problems with the non-stationarity mentioned earlier. If a match is still impossible to obtain, the candidate providing the lowest misfit is retrieved and "flagged". During post-processing the flagged cells 

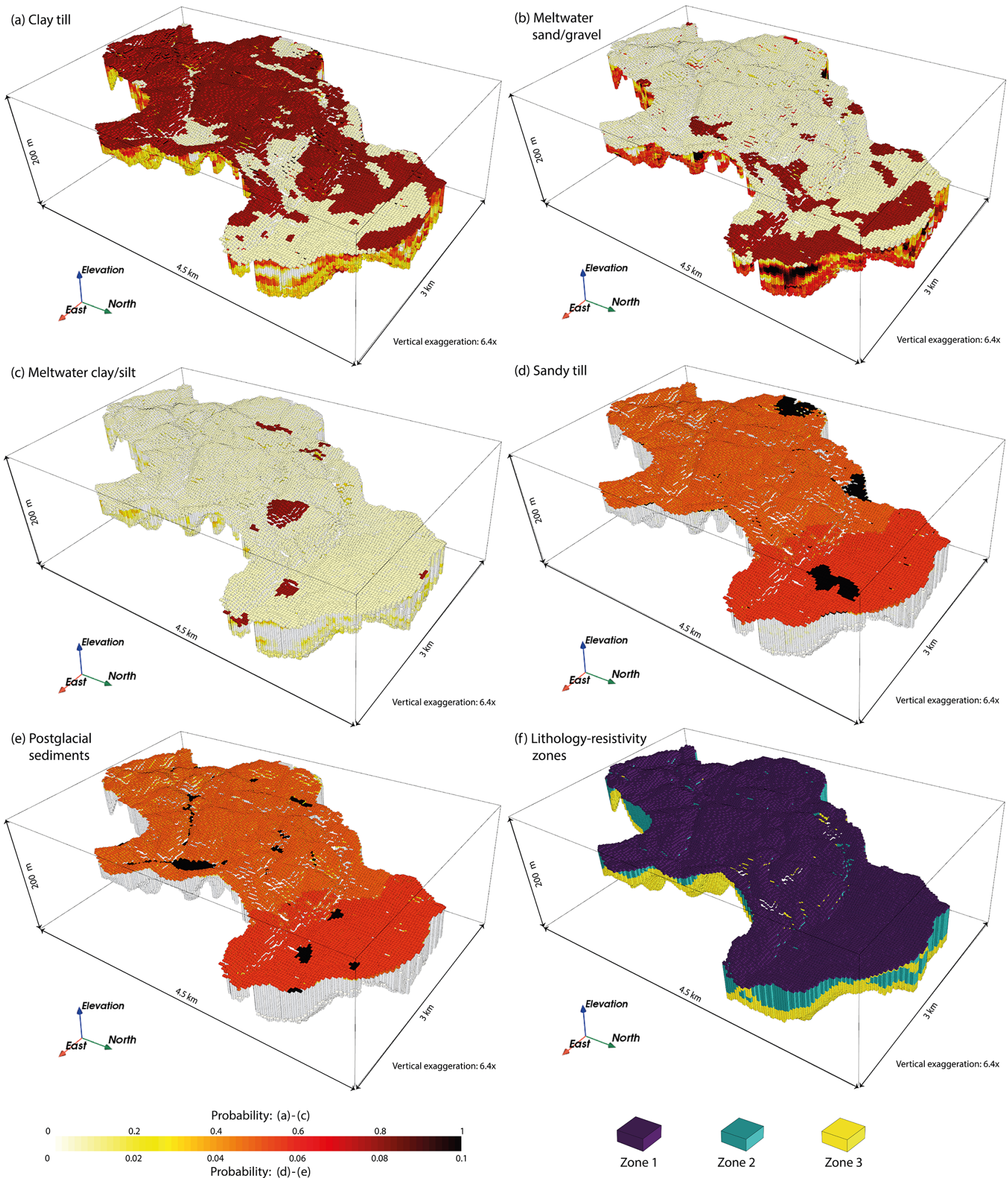

Figure 9. (a-e) Soft data probabilities of geology for the buried valley element. Soft data probabilities calculated from the surface geology and tTEM data available. Note the smaller range in the color scale of the sandy till (d) and postglacial sediments (e). 
Table 4. Conversion rates for soft data in the conditional realization.

\begin{tabular}{lllllll}
\hline $\begin{array}{l}\text { Soft data probability for } \\
\text { a single lithology group }\end{array}$ & 0.5 to 0.6 & 0.6 to 0.7 & 0.7 to 0.8 & 0.8 to 0.9 & 0.9 to 1 \\
\hline $\begin{array}{l}\text { Conversion rate of soft } \\
\text { to hard data }\end{array}$ & $2 \%$ & $3 \%$ & $4 \%$ & $5 \%$ & $6 \%$ \\
\hline
\end{tabular}
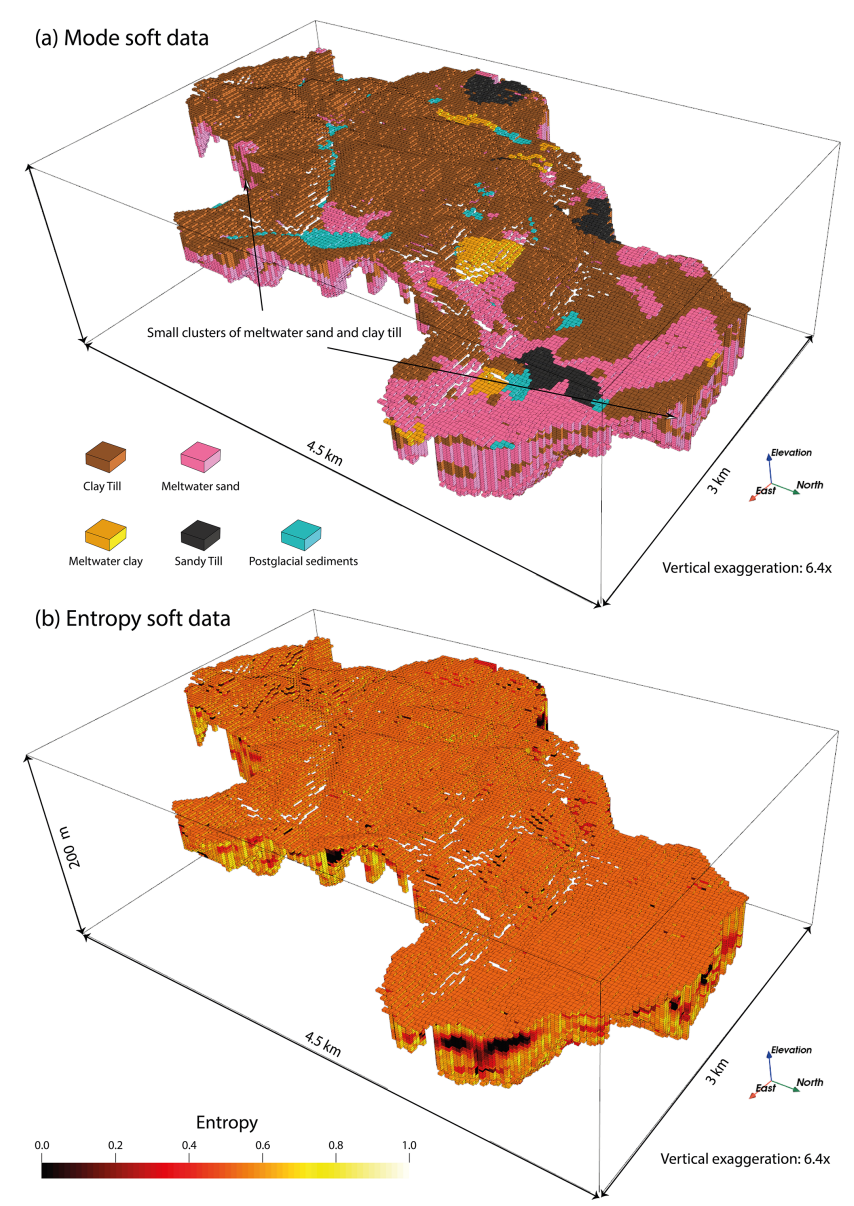

Figure 10. (a) Mode and (b) entropy for soft data from Fig. 9. Low entropy (certainty) is marked with black color, while white colors represent high entropy (uncertainty).

are simulated again using the same simulation setup and TIs. Because the larger structures are placed during the initial simulation, the flagged cells in postprocessing have a higher probability of finding a matching event in the training image, which minimizes the appearance of simulation artifacts.

- The path at which the simulation grid nodes are visited needs to be selected. We choose a random path as is often used in MPS. When combined with conditional hard data, the random path preferentially first visits nodes that are in the vicinity of hard data. This is achieved by calculating distances to hard data and then randomly drawing nodes according to these distances to create the visitation path (Straubhaar, 2019). This ensures that especially hard data from the surface have a higher impact on the final realizations.

As pointed out by Tahmasebi (2018), a quantitative evaluation of the performance of MPS is still unresolved, and the effect of the simulation algorithm parameterization remains an area of active research (Juda et al., 2020). To ensure that the combination of TI and MPS algorithm produces the soughtafter spatial variability, we simulate 10 independent realizations without including the conditioning data, i.e., two realizations from the prior model. We adopt the heuristic strategy of Høyer et al. (2017), making sure that the realizations from the prior model are in accordance with and represent our expectations of both redox and geology. Two unconditional realizations from the prior model are shown in Fig. 11. The spatial variability and patterns seen in the TIs (Fig. 4) are generally represented for both redox and geology. As expected in the TI and conceptual model for geology, the prior realizations show primarily horizontal stratification. In the buried valley infill, the extent of geological layers and redox structures is more limited than in the Quaternary sequence, which is also in accordance with our conceptual understanding. In the Quaternary sequence, the geological layer order is correct, with clay till predominantly found near terrain, while meltwater deposits are the main constituent of the deeper parts. Both sandy till (black) and postglacial sediments (blue) only occur near the surface in accordance with the TIs, much more infrequently than portrayed.

For redox, the layer order from the TI is likewise preserved in the unconditional realizations such that oxic conditions are found primarily at the surface with increasing $\mathrm{N}$-reducing and reduced conditions at lower depths. The prior model also captures the possibility of secondary redox zones from geological windows that are portrayed in TI1. N-reducing conditions are found adjacent to oxic conditions at the surface and not in the bottom of the simulation domain in the unconditional realizations. The overall redox conditions can be visualized by plotting the accumulative probability for redox conditions as a function of depth, constructed by summarizing over both realizations, which hence provides the 1D marginal distribution in all voxels. This marginal distribution is accumulated with depth as shown in Fig. 12. Fewer oxic and $\mathrm{N}$-reducing conditions (orange and green) are simulated in the prior model at the surface and do not stretch as far 
down as portrayed in the TIs (Fig. 12a), which can also be visually confirmed by comparing Figs. $4 \mathrm{~b}$ and $11 \mathrm{~b}$ and $\mathrm{f}$.

Due to the strict vertical layer ordering in the TI, the nonstationary characteristics are preserved in the unconditional realizations despite the expectation of a stationary training image in MPS. We suspect that the full scan of the training image helps to provide the necessary configurations to enable a more non-stationary output in the prior realization. However, the MPS algorithm cannot fully capture all the nonstationarity of the TIs as there is a tendency to simulate fewer oxic conditions at the surface along with sandy till and postglacial sediments being underrepresented. Furthermore, the size of the TIs may hinder the reproduction of large-scale connected structures such as the oxic conditions at the surface (de Vries et al., 2009). This tendency is hence beyond immediate remediation by changing any of the fundamental parameters in direct sampling but can instead be guided by the incorporation of conditioning data in the posterior model (Barfod et al., 2018). In summary, we conclude that the current parameterization of the direct sampling algorithm provides the spatial variability that fits our understanding of the system, albeit with some slight caveats. With the current simulation setup, flagging occurs for approximately $8 \%$ of the cells during initial simulation and $4 \%$ after post-processing. We emphasize that the unconditional realizations represent the prior information of the system, not the TIs nor the exact parameters chosen in the DeeSse algorithm.

\section{Modeling results}

In this section, we present the modeling results from the set of posterior realizations of both geology and redox where the information from the prior model is conditioned to the data. We condition the simulation to the hard and soft data presented in Sect. 5.4.

Figure 13 shows two conditioned realizations from the posterior model. The impact of introducing the conditioning data is immediately seen at the surface of the geology simulations (Fig. 13a and e), which is guided to a large degree by the information from the surface geology map. The architecture stays relatively fixed between the realizations, and variability is predominantly small scale. Given the high number of conditioning data, this is not unexpected. The main part of the Quaternary sequence element is covered by an approximately $8-10 \mathrm{~m}$ (sometimes reaching more than $20 \mathrm{~m}$ ) thick clay till, followed by meltwater deposits. These meltwater deposits exhibit a shorter correlation length than in the prior model as seen in Fig. 13g. The lateral extent of layers in the buried valley is less than in the Quaternary sequence but not as significant as in the prior model. In general, the amount of meltwater clay/silt in the posterior model is lower than in the prior model, and the realizations consist mostly of either clay till or meltwater sand/gravel. This change is due to information from the geology soft data which is heavily dominated by clay till and meltwater sand/gravel (Fig. 9). In fact, in zones of high resistivity, the soft data are the dominant constraint on the realizations with meltwater sand/gravel causing low variability between the two realizations as seen in, e.g., Fig. 13a and e. Just northwest of the high resistive zone in the buried valley is an area with more ambiguous resistivities which leads to greater variability and more dependency on the prior model. The bottom of the simulation domain is mainly made up of meltwater sand/gravel, which is likely information stemming from the prior model.

Due to the joint simulation of geology and redox in the current setup, the overall redox architecture in the realizations is coherent with the geology as outlined in the TI. For example, postglacial sediments are attributed to reducing conditions, and meltwater sand/gravel is likely oxic at the surface. This consistency explains the predominantly oxic conditions at the surface seen in the sandy part of the buried valley (Fig. 13b and f). In the Quaternary sequence, the clay till at the surface shows both oxic and reduced conditions as indicated in the TIs (Fig. 13d). Oxic conditions are clearly more present at the surface of the posterior model than in the prior realizations. The oxic conditions are distributed in the low-gradient parts of the simulation domain, whereas reduced conditions are found along depressions in the landscape such as valleys and streams (Fig. 13b), which is in good accordance with our geochemical understanding of the system. The entire posterior redox probability profile in Fig. 12c also resembles the TI profile better than the prior model. Because there are no soft data aiding the occurrence of N-reducing conditions in the posterior model, it inherits the capacity of simulating $\mathrm{N}$-reducing conditions from the prior model and is simulated less than in the TI profile from Fig. 12. Thus, N-reducing conditions are also simulated adjacently to oxic conditions as in the prior model. The overall redox architecture is in place with planar-type redox conditions in the buried valley and geological window-type conditions in the Quaternary sequence (Fig. 13d). However, sole voxels of oxic conditions in the deeper parts of the realizations appear as unwanted simulation artifacts (Fig. 13h). Because these artifacts happen infrequently, are tiny and are surrounded by reduced conditions, we argue that for $\mathrm{N}$-retention simulations these artifacts may be negligible.

In total, we simulate 100 realizations like those presented in Fig. 13, which together are used to represent the full posterior model. To summarize the posterior model, we present ensemble statistics (from Sect. 4.2) in Fig. 14. The entropy of geology (Fig. 14c) at the surface is 0 at most locations due to the hard data provided from the surface geology map. The more uninformed parts of the surface (lighter colors) correspond to the buffer zone in the surface geology map. The entropy is usually around $0.2-0.3$, indicating that most realizations of the posterior model provide the same outcome in the buffer zone. In a few places along the buffer zone, an entropy level of 0.8 is reached, indicating that these voxels have a near-uniform distribution among several different categories 

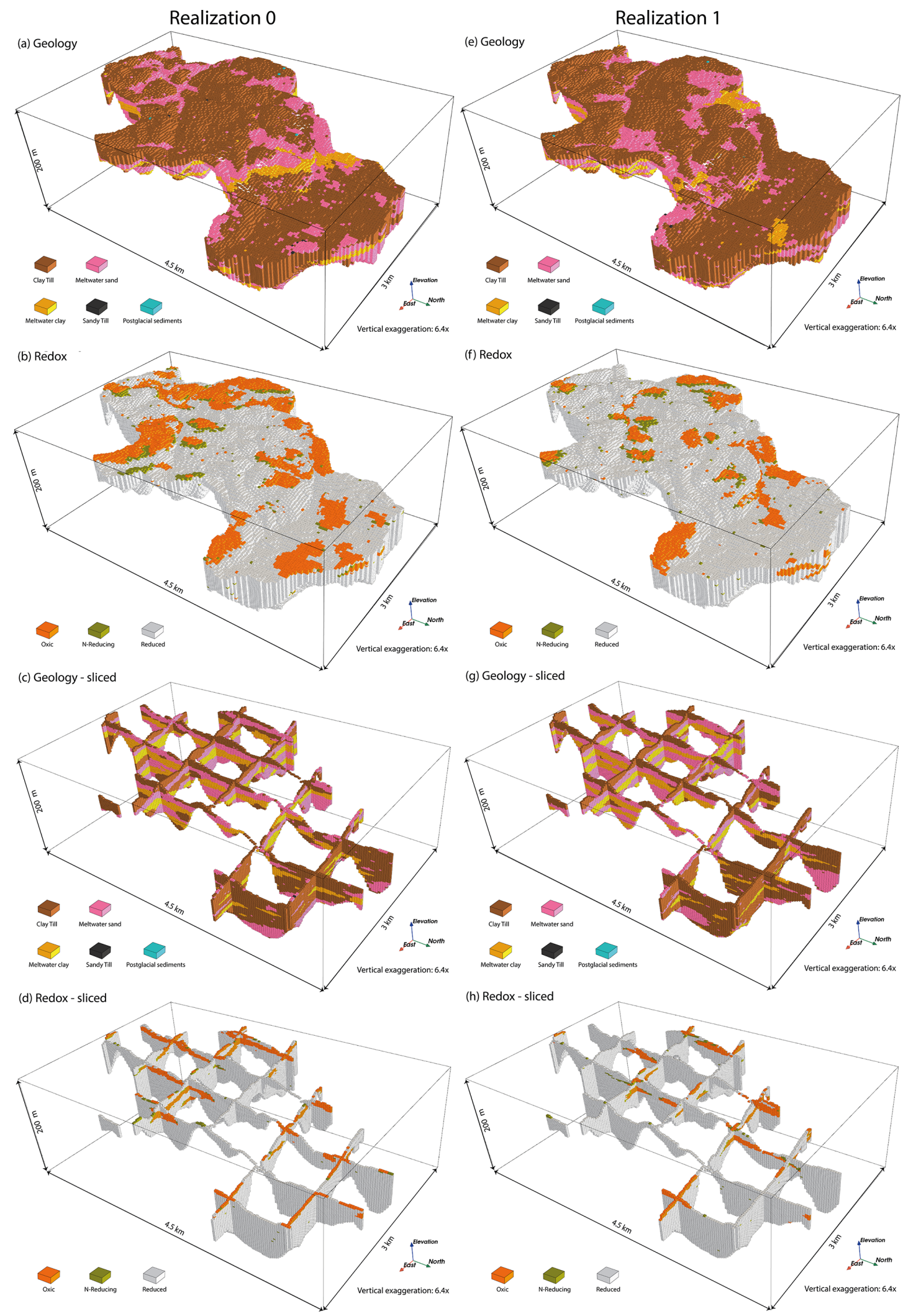

Figure 11. Two unconditional realizations from the prior model. (a, b) One realization of jointly simulated geology and redox. (c, d) The same realization sliced in the $x$ and $y$ directions. (e-h) Same figure configuration as in (a-d) but for a different realization. 

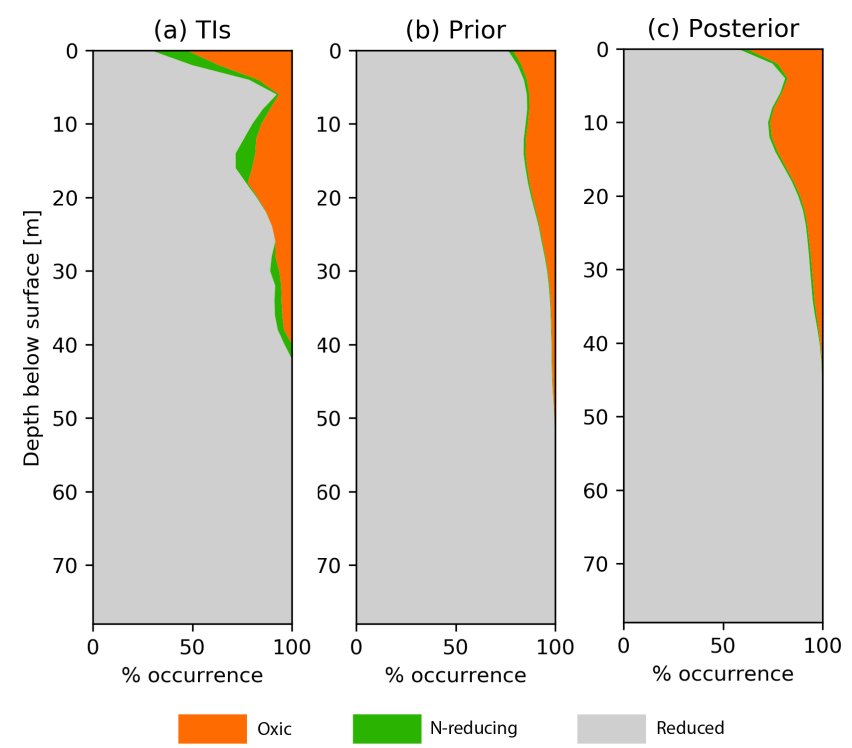

Figure 12. Accumulative probability profiles of redox conditions in the study area for (a) TIs, (b) prior distribution and (c) posterior distribution.

to the one shown in the mode model. This confirms the qualitative results from inspecting the individual realizations that the effect of introducing prior information and hard data increases the information content (lowers entropy) of the final models drastically compared to the soft data only (Fig. 10). For the lower part of the simulation domain, the posterior model shows higher entropy than at the surface. This means that the mode found in this region is usually more uncertain. In some areas of high resistivity, we also see very low entropy at depth, where the soft data provide the main architectural input and the posterior mode model resembles the soft data mode. The effects of introducing the prior information for the architecture are clearly seen in the coherent structures produced in the posterior mode, in contrast to the patchiness of the mode in Fig. 10a.

The redox mode does not display some of the minor simulation artifacts seen in the individual realizations, because these are averaged out over many realizations. Instead, we do see remnants of the converted oxic soft data at the surface of the mode model (Fig. 14b) with zero entropy (Fig. 14d). This is clearly a side-effect of the soft data conversion, since these sole oxic voxels are not in accordance with the overall pattern of reduced conditions along the streamlines and valleys. The redox mode shows few N-reducing conditions, in accordance with the redox depth profiles shown in Fig. 12c, demonstrating the inclination to simulate either oxic or reduced conditions in the posterior model.

Overall, the entropy of redox shows a reverse pattern to that of geology. The redox entropy is highest near the surface and decreases with increasing depth (Fig. 14d). One could at first expect the highest redox uncertainty at deeper depth because the density of the hard data is much higher near the surface and, for the deeper part of the architecture, the geochemical data are rarely available. However, the entropy sharply decreases in the reduced zone beneath a certain depth. This pattern instead fits well with the conceptual understanding of the redox structure evolution: oxic conditions are developed as oxidants (e.g., oxygen and nitrate) infiltrate from the root zone to the subsurface, where reduced layers are present. Therefore, a redox front propagates downward and, under homogeneous conditions with vertical flow of water, it would be unlikely to develop oxic conditions below the redox front, while the spatial heterogeneity of the geological settings of the near-surface environments at various scales (pore scale to landscape) has been well documented (e.g., Baveye et al., 2018; Groffman et al., 2009; Sexstone et al., 1985), implying highly heterogeneous redox conditions at the shallower depth. The sharp decrease in entropy of the buried valley takes place due to the planar redox-type domain in the buried valley, whereas the possibilities of geological windows in the Quaternary sequence make the high entropy section develop further down. Some of the voxels at the surface of the Quaternary sequence element depart from the overall pattern by having a very low entropy. This trend is likely aided by the soft data, giving high probabilities of oxic conditions at the surface. The high entropy at the surface is likely also aided by the soft data. At the surface and down to about $10-20 \mathrm{~m}$ of the buried valley, we generally do not know much about the redox conditions, as indicated by the white yellowish colors in Fig. 14. The more evenly distributed redox soft data probabilities (Table 3 ) could explain some of this high entropy.

\section{Discussion}

To our knowledge, examples of simulating redox conditions with sediment-texture distributions using multiple-point geostatistical methods have not been shown before. This study sets out with the aim of proposing and reviewing a methodology for modeling both redox architecture and geology simultaneously in high-resolution 3D using MPS.

\subsection{Simulation artifacts}

The spatial variability of the TIs is represented in the prior realizations, and conditioning data guide our expectations of the system to a posterior model. In some cases, due to the limited size of the TI, inconsistencies between conditioning data and the prior model exist. In some cases, these inconsistencies lead to simulation artifacts in the realizations but are rare since they are largely corrected during MPS postprocessing. For the posterior model realizations, flagging is decreased to only about $5 \%-6 \%$ after post-processing while happening $19 \%-22 \%$ of the time during the initial run of the algorithm. Some simulation artifacts also occur in the prior model itself and therefore cannot alone be attributed to in- 

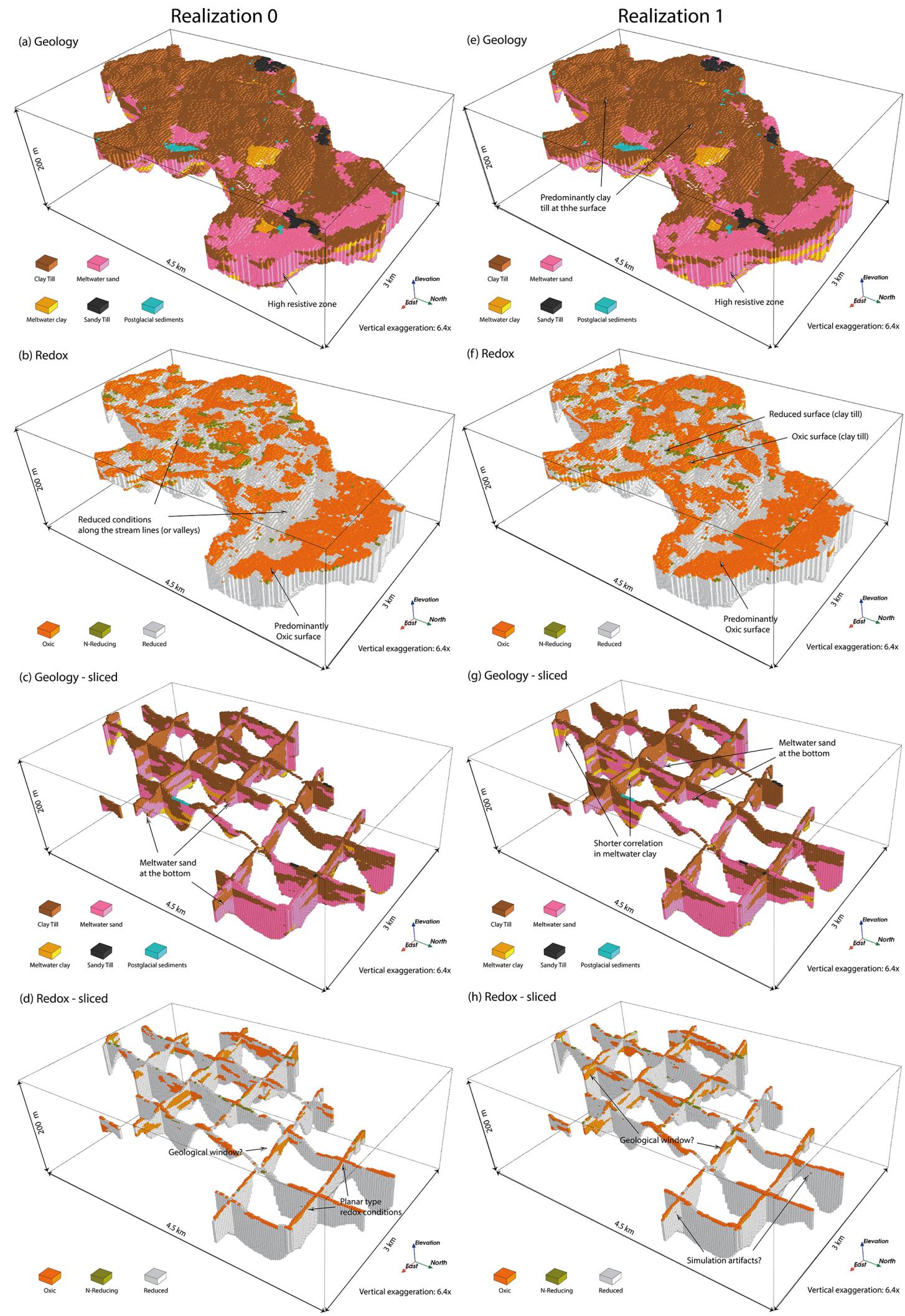

Figure 13. Two conditioned realizations from the posterior model. (a, b) One realization of jointly simulated geology and redox. (c, d) The same realization sliced in the $X$ and $Y$ directions. (e-h) Same figure configuration as in (a-d) but for a different realization. 

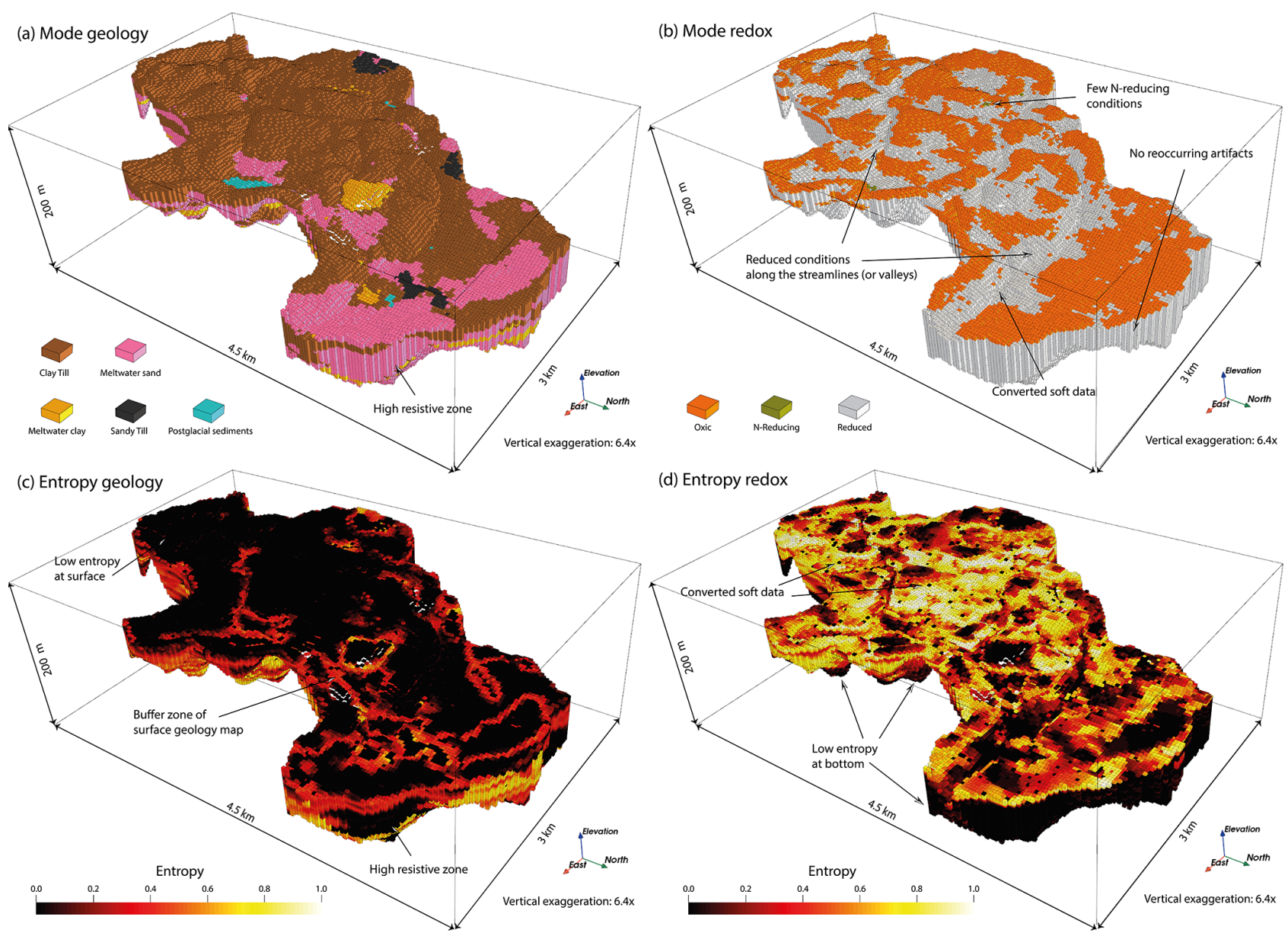

Figure 14. Mode and entropy of 100 geology and redox realizations. Low entropy (certainty) is marked with black color, while white colors represent high entropy (uncertainty).

consistencies between the prior model and the conditioning data, which is underlined by the decrease in flagging that also happens during post-processing of the prior model realizations. These inconsistencies are associated with a lack of matching events in the TI. To remedy such simulation artifacts, one either needs larger TIs to allow more spatial variability or artificially enhance the variability by lowering the number of conditional data to consider when searching for a match in the MPS algorithm. In the latter case, this will happen at the cost of reproduction of the actual spatial variability portrayed in the TI. We argue that, in the current nitrate simulation at the catchment scale, these artifacts do not affect the overall architecture (Fig. 14) and redox trends with depth (Fig. 12). It is also expected to have negligible impact on hydrological modeling as the overall architecture allows groundwater flow to pass by such artifacts. Nevertheless, future studies are required to reduce artifacts of this kind or, at least, downplay their significance. One solution could be to allow rotation during simulation that could offer more configurations during simulation. However, testing with a setup allowing $360^{\circ}$ rotation in the horizontal plane did not enable a substantial improvement of this issue. The flexibility of the current methodology also allows the inclusion of soft data probability maps through Eq. (2), indicating spatial restrictions on certain lithologies or redox conditions, which could potentially remedy some of the deeper-lying artifacts.

\subsection{The role of soft data}

The random path has a tendency to underestimate soft data and provide less resolution in the results compared to other path types (Hansen et al., 2018). In the current study the amount of soft data coverage was high (more than $43.5 \%$ of the simulation grid). To utilize the abundant soft data, we randomly converted a fraction of the soft data into hard data to compensate for the underestimation from the path. This helped transfer more weight towards the soft data during simulation, with the caveat of introducing converted soft data in unwanted positions, such as oxic in an overall reduced environment. This problem is however mostly encountered in the redox mode (Fig. 14b) and does seemingly not pose as big of a problem for the individual realizations in Fig. 13b and f. By 
further processing the realizations by removing any sole voxels that differ from the neighboring voxels, this problem can be removed entirely but at the risk of removing actual sole voxels. One could also randomly select a new set at each iteration, although this is not directly implemented in the DeeSse software and still would not make sure that soft data in general are handled correctly. For instance, the current remediation only handles lithology groups with probability $\geq 50 \%$ and thereby cannot help improving the information content for any categories with probability $<50 \%$. This affects, e.g., $\mathrm{N}$-reducing conditions at the surface where soft data probabilities are substantially lower (Table 3). Thus, N-reducing conditions are bound to be underrepresented since they are not converted from soft data, which is the tendency shown in the posterior redox profile compared with the TI (Fig. 12). Despite the clear advantages of converting some soft data to provide more emphasis on them, the current simulation results could most likely be improved by better incorporating the soft data information in general. However, neither a preferential path that visits voxels with soft data information before other voxels nor the use of non-collocated soft data is currently implemented in most state-of-the-art MPS algorithms. The problem of how to best incorporate soft data information hence reaches beyond the current study. We encourage this to remain an active area of research to make MPS relevant for practitioners without the need for too much ad hoc remediation.

\subsection{Resistivity-lithology relationship}

The established resistivity-lithology relationship allows us to map the prior probabilities of each lithological group based on the tTEM in the simulation area. Utilizing tTEM as soft data information ensures that it does not have too much influence over the final results. Here, the relationship is inferred from the resistivity grid and training images. When simulating, the general mismatch between the training image patterns (based on interpreted geology) and the tTEM data is thus minimized. Methods exist for establishing a relationship between resistivity and clay content (Christiansen et al., 2014; Foged et al., 2014). Unfortunately, this is not directly applicable for the lithological groups used here as they are not defined on the basis of the clay content. Alternatively, this relationship could be inferred using boreholes near the study site. Similarly to the approach in this study, inferring the resistivity-lithology relationship from boreholes is typically based on deriving probabilities from histograms (Barfod et al., 2016; Gunnink and Siemon, 2015; X. He et al., 2014). In accordance with the present results, these studies also show a significant overlap between different lithologies, and as such using nearby boreholes for inferring the resistivity-lithology relationship would mainly minimize the reuse of data and avoid subjectivity carried over from the TIs.

\subsection{Geological modeling subjectivity and data reuse}

The inclusion of geological mapping experts in the creation of TIs introduces modeling subjectivity. Thus, the final realizations could include unverifiable modeling choices following the interpretation procedure in cognitive modeling. Through experiments with geological interpretation of the uncertainty in boreholes, Randle et al. (2019) argued that expert elicitations do not result in accurate predictions of interpretation error. Schaaf and Bond (2019) propose the quantification of interpretation uncertainty for inclusion in geostatistical simulation, while efforts have been made to make TI generators (Pyrcz et al., 2008) and data-driven TIs without the need for expert knowledge (Vilhelmsen et al., 2019). However, our approach of process-based TI generation from expert elicitation is a common approach in MPS applications (Mariethoz and Caers, 2015). A possible explanation for this is the benefit of bringing in prior expert knowledge, which is otherwise difficult to quantify. This ensures that results are in accordance with as much information as possible (Curtis, 2012; Tarantola, 2005) and realizations are not in clear conflict with geological concepts (Jessell et al., 2010; Wellmann and Caumon, 2018).

Despite the potential subjectivity in the geological modeling of the study area, these modeling choices are primarily guided by data. The tTEM data collected in this study have, e.g., contributed to a good correlation between the terrain and the subsurface architectures in the geological interpretations. These observations fit well with the current knowledge of the latest geological events in the area, thus providing good possibilities of making robust geological correlations between the geological and geophysical data.

It might be difficult to quantify the effect of the apparent loss in degrees of freedom that follows from using the same data for establishing the prior information and as condition data during simulation. In the current study, the problem of reusing data for outlining geological elements is most likely not critical as only large-scale structural information is partly interpreted from the resistivity data, such as the top of the Paleogene clay layer. The degrees of freedom loss for reusing the resistivity information in the TIs and as conditioning data in simulation is undoubtedly larger. Although the small size of the TIs may pose a problem for reproducing the intended variability, in this instance it acts to limit the effect of reusing data. This issue persists for approximately $33 \%$ of the total voxels (Table 2).

\subsection{Training images and geological elements}

If possible, the TI should provide all possible dimensions and shapes of the geological features in the subsurface (Strebelle, 2012). However, sizes of the TIs in the current setup are relatively small compared to the simulation grid and hence do not contain that many configurations. In general, the smaller the TI, the fewer possible structures can be represented (Mari- 
ethoz and Caers, 2015). We consider two remedying factors. Firstly, the simplicity of the TI. In the study area, we expect a geology with continuous clay and sand units partly restrained by incised valley structures in the Paleogene clays as seen in Fig. 3. Even though the TI is small and simple, it conveys the general pattern to be expected in geological features throughout the simulation domain. The simplicity should alleviate some of this issue, although in an area with more expected heterogeneity, a more diverse and larger TI would be needed. Secondly, if the geological variability provided in the TI is not sufficient, algorithmically induced variability measures such as scaling and rotation of features is possible with direct simulation (Mariethoz et al., 2010).

The non-stationarity of both sets of TIs is evident. This is a common problem when designing training images directly based on and mimicking geology, which is inherently non-stationary. This might pose a problem, as only a certain number of the configurations in the TIs will produce a match during the direct simulation. Consequently, we might risk reproducing larger parts of the TI in the realizations. Such verbose copying is partially remedied by the addition of conditioning data and choosing a smaller search radius as argued in Vilhelmsen et al. (2019). However, a smaller search radius comes at the price of not reproducing the features in the TI and adding variability more related to algorithmic choices than geological variability. Luckily, plenty of conditioning data are available for the simulations to remedy some of the shortcomings of the training images. As argued in de Vries et al. (2009), subdividing the TIs and simulation domain into different areas is another possibility for handling non-stationarity. To some degree, the geological elements represent such a subdivision of the entire modeling domain in the study area.

In the current study, we considered the boundaries between the geological elements fixed. In reality, there is some interpretation uncertainty related to these boundaries, especially in data-scarce areas. Future studies may be able to quantify this uncertainty. If this uncertainty is sufficiently large such that it affects the simulation results significantly, we put forward the idea of re-simulating boundaries between geological elements as part of the simulation.

Because TIs are attributed to a specific geological element, these TIs may be reused in other simulation studies with comparable geological elements, and we therefore strongly recommend building a TI library. This approach would alleviate the most fundamental of the issues in the current setups. Information between TI and data becomes independent when using a generalized TI. Specifically, the reuse of data (in constructing the TI and implicitly when inferring the resistivitylithology relationship) is eradicated. For a smaller geological element, the TIs developed in the study area may also represent a proportionally larger portion of the expected variability. An additional bonus would be a reduction in labor/time since TIs are pre-existing or maybe only need slight alteration.
Conceptual TIs or those based on data from another study area would most likely be preferable from a geostatistical point of view as it would ensure independence of information. However, in the case of a TI based on nearby data, the TI should be close enough to the study area such that the depositional and redox setting are comparable. Furthermore, the study of Barfod et al. (2018) suggests that TIs become secondary given a high amount of conditioning data. In future studies and if a similar approach of TI creation within the simulation domain is chosen, we recommend collaborative efforts between geologists and geochemists in securing the best possible location for representative TIs. We also suggest that the level of detail in the TI should be case-specific, involving a trade-off between the time to construct the TI, the level of support in the available data, the background knowledge, limitations due to size and how well the features can be reproduced with the chosen parameterization.

\subsection{Computationally attractive stochastic simulations}

In the current setup, simulations are computationally feasible. One hundred realizations of both elements are generated in less than $2.5 \mathrm{~h}$ on a high-end personal laptop (Intel(R) Core(TM) i7-8850H CPU @ 2.60 GHz, 6 cores (12 threads) with 10 threads allocated to DeeSse. The average simulation time for a single realization is hence just over $80 \mathrm{~s}$. Several factors contribute to this: (1) the relatively small TIs making the number of possible combinations limited, (2) the restriction on a maximum of 20 conditioning points and (3) the subdivision of the simulation grid into geological elements. Some of the abovementioned factors are algorithm tuning parameters, while others are added bonuses of understanding the geology in question (e.g., the ability to break the problem up into smaller bits and choose an acceptable level of simplicity in the models). In this case, bringing expert field knowledge to the modeling setup is advantageous.

\subsection{Multi-purpose modeling results through uncertainties}

The proposed workflow allows incorporation of quantified uncertainties into the input data and structural uncertainties in the subsurface models. This is a major advantage over, e.g., static models. We specifically dealt with prior uncertainty in the geological and redox conditions as portrayed in the TIs and geological map and resistivity data (soft data). Other sources of error (e.g., modeling and measurement errors) in the input data can also be explored, as MPS offers a flexible setup for treating data with uncertainties. Additionally, it is clearly shown in the comparison between mode and entropy of posterior and soft data that MPS adds additional valuable information through the TIs that enable geologically viable architecture, especially in cases where soft data are too weak to provide significant support. The quantitative description of uncertainties as portrayed by the final ensemble 
of realizations also has many useful properties for additional analysis. For instance, the ability to produce redox profiles as in Fig. 12 is trivial once the simulation is completed. These redox profiles make comparisons with previous studies possible while offering many other possibilities for summary statistics and quantifying uncertainty. This flexibility in the final analysis is one of the main benefits of applying geostatistical mapping of redox conditions (and geology). With the current methodology, depth profiles can also be calculated for specific sets of $x$ and $y$ coordinates to investigate some of the spatial variation in redox. Another example would be to investigate the distribution of redox conditions in the geological groups, which allows assessment of new hypotheses on the coupling between geology and redox. It may also reveal insights into the spatial dependencies of such couplings and showcase potential geological windows for oxic conditions at depth. Entropy gives insight into the nature of information content, and therefore it would be an active tool in finding the best spot for further investigation, i.e., showing where information is lacking. For instance, in the case of redox, entropy might be suited to assisting a focused field campaign in retrieving more information of redox in the buried valley element. In the current case, the Quaternary sequence in many places showed a lack of information in the first $10-20 \mathrm{~m}$ that is typically critical to model.

From the study area, it seems that it is possible to create a computationally feasible joint stochastic 3D high-resolution model of redox and geology with the current setup. However, these findings cannot be extrapolated directly to other study areas. Future research includes testing the method in other catchment areas to assess the robustness and general applicability. Many improvements, besides fine-tuning algorithm parameters, also exist. We, e.g., expect improvements and minor changes to the overall setup, as different study areas will contain site-specific challenges that should be addressed. As mentioned, one of the current issues that need to be addressed is how best to quantify and integrate soft data. Besides the resistivity-lithology relationship, we also recognize the need for an extensive study on the quantification of uncertainty in geological maps such as the geological surface map presented here, but it is beyond the scope of the current study.

\section{Conclusions}

This study sets out to model both redox architecture and geology simultaneously in high-resolution 3D due to the dependency of the evolution of the subsurface redox conditions on the hydrogeological pathways. This is achieved using a bivariate MPS simulation. MPS modeling with a bivariate TI of geology and redox presents some important features compared to previous mapping studies: (1) MPS effectively produces geology and redox following expectations and (2) TIs provide an intuitive and easy collaboration across different fields of expertise. Valuable expert information, otherwise difficult to quantify, is seamlessly integrated within MPS. This ensures in our case that there is a correspondence between geology and redox conditions, which is one of the key strengths of the proposed methodology. Although challenges in the current approach exist, we conclude that the proposed methodology offers improvements to existing methods for mapping geology and redox by producing consistent realizations of both variables. The flexibility of the geostatistical results as represented by the ensemble of realizations allows comparisons with traditional mapping techniques. We interpret and model individual sedimentary layers into coherent volumes ("geological elements") that greatly help to guide our simulation results and reduce computation costs. This new mapping technique should aid our understanding of the uncertainties and limitations of our knowledge and data. High-resolution 3D understanding of both redox and geological architecture will likely improve predictions of $\mathrm{N}$ retention and water pathways in the subsurface. The generalizability of these results is subject to certain limitations as the proposed workflow is only tested on a single study site. This study lays the groundwork for future research into coupled understanding of geology and redox using MPS. Despite its exploratory nature, this study offers valuable insights into the feasibility of joint geostatistical modeling of redox and geology. Several questions remain to be answered regarding interdependence between different sets of quantified information and integration of soft data. The geological and redox architecture simulations might be incorporated into hydrological modeling with $\mathrm{N}$ transport to be used for $\mathrm{N}$-retention mapping of the subsurface important for future more targeted $\mathrm{N}$ regulation of agriculture.

Code and data availability. All files needed for running the MPS simulation software are available through Madsen (2021). The files can be run through the DeeSse software (https://www.ephesia-consult.com/portfolio/deesse/, Ephesia consult, 2021). The geophysical datasets (excluding the tTEM survey) are publicly available through the Gerda database (https://eng.geus.dk/products-services-facilities/data-and-maps/ national-geophysical-database-gerda GERDA, GEUS, 2021), while the borehole information is publicly available through the Jupiter database (https://eng.geus.dk/products-services-facilities/ data-and-maps/national-well-database-jupiter Jupiter, GEUS, 2021). The surface geology map can be retrieved freely from the Maps of Denmark service of GEUS (https://eng.geus.dk/products-services-facilities/data-and-maps/ maps-of-denmark/pricelist, Maps of Denmark, GEUS, 2021). The elevation model of Denmark is provided by the Danish Agency for Data Supply and Efficiency and is publicly available (https://kortforsyningen.dk/indhold/english, SDFE, 2021). Due to the project policy of Mapfield, the tTEM survey data are not yet publicly available but will be at a later stage after the end of the project released to the Gerda database. 
Author contributions. RBM, HK and AJK have been primarily in charge of methodology development. The idea of using geological elements at the site was conceptualized by PS. Geological modeling was carried out by AJK with the assistance of PS, while HK carried out the geochemical analysis under the assistance of BH. IM and AVC provided valuable insights into geophysical data and models. TMH and TNV provided crucial sparring on geostatistical modeling from an applied and theoretical perspective. RBM developed the model setup and performed the simulations, with quality control on the final realizations by HK, PS and AJK. RBM prepared the first draft of the manuscript with contributions from all the co-authors.

Competing interests. The authors declare that they have no conflict of interest.

Acknowledgements. The authors would like to thank the MapField project (http://www.mapfield.dk, last access: 15 May 2021) for making data available and supporting the current research. We thank the two reviewers for thorough and constructive feedback during the revision of the manuscript. We also thank the Independent Research Fund Denmark (grant no. 7017-00160B) for supporting the research efforts of Thomas Mejer Hansen in the current study

Financial support. This research has been supported by the Innovation Fund Denmark (grant no. 8855-00025B).

Review statement. This paper was edited by Fabrizio Fenicia and reviewed by Donald A. Keefer and one anonymous referee.

\section{References}

Abbaspour, K. C., Yang, J., Maximov, I., Siber, R., Bogner, K., Mieleitner, J., Zobrist, J., and Srinivasan, R.: Modelling hydrology and water quality in the pre-alpine/alpine Thur watershed using SWAT, J. Hydrol., 333, 413-430, https://doi.org/10.1016/j.jhydrol.2006.09.014, 2007.

Alcalde, J., Bond, C. E., Johnson, G., Butler, R. W. H., Cooper, M. A., and Ellis, J. F.: The importance of structural model availability on seismic interpretation, J. Struct. Geol., 97, 161-171, https://doi.org/10.1016/j.jsg.2017.03.003, 2017.

Auken, E., Christiansen, A. V., Westergaard, J. H., Kirkegaard, C., Foged, N., and Viezzoli, A.: An integrated processing scheme for high-resolution airborne electromagnetic surveys, the SkyTEM system, Explor. Geophys., 40, 184-192, https://doi.org/10.1071/EG08128, 2009.

Auken, E., Christiansen, A. V., Kirkegaard, C., Fiandaca, G., Schamper, C., Behroozmand, A. A., Binley, A., Nielsen, E., Effersø, F., Christensen, N. B., Sørensen, K. I., Foged, N., and Vignoli, G.: An overview of a highly versatile forward and stable inverse algorithm for airborne, ground-based and borehole electromagnetic and electric data, Explor. Geophys., 46, 223-235, https://doi.org/10.1071/EG13097, 2015.
Auken, E., Foged, N., Larsen, J. J., Lassen, K. V. T., Maurya, P. K., Dath, S. M., and Eiskjær, T. T.: tTEM - A towed transient electromagnetic system for detailed 3D imaging of the top $70 \mathrm{~m}$ of the subsurface, Geophysics, 84, E13-E22, https://doi.org/10.1190/geo2018-0355.1, 2019.

Barfod, A. S., Møller, I., and Christiansen, A. V.: Compiling a national resistivity atlas of Denmark based on airborne and groundbased transient electromagnetic data, J. Appl. Geophys., 134, 199-209, https://doi.org/10.1016/j.jappgeo.2016.09.017, 2016.

Barfod, A. A. S., Vilhelmsen, T. N., Jørgensen, F., Christiansen, A. V., Høyer, A.-S., Straubhaar, J., and Møller, I.: Contributions to uncertainty related to hydrostratigraphic modeling using multiple-point statistics, Hydrol. Earth Syst. Sci., 22, 54855508, https://doi.org/10.5194/hess-22-5485-2018, 2018.

Baveye, P. C., Otten, W., Kravchenko, A., Balseiro-Romero, M., Beckers, É., Chalhoub, M., Darnault, C., Eickhorst, T., Garnier, P., Hapca, S., Kiranyaz, S., Monga, O., Mueller, C. W., Nunan, N., Pot, V., Schlüter, S., Schmidt, H., and Vogel, H. J.: Emergent properties of microbial activity in heterogeneous soil microenvironments: Different research approaches are slowly converging, yet major challenges remain, Front. Microbiol., 9, 1-48, https://doi.org/10.3389/fmicb.2018.01929, 2018.

Blicher-Mathiesen, G., Holm, H., Houlborg, T., Rolighed, J., Andersen, H. E., Carstensen, M. V., Jensen, P. G., Wienke, J., Hansen, B., and Thorling, L.: Landovervågningsoplande 2018, NOVANA, Aarhus Universitet, DCE - Nationalt Center for Miljø og Energi, Videnskabelig rapport nr. 352, 241 pp., 2019 (in Danish).

Bond, C. E.: Uncertainty in structural interpretation: Lessons to be learnt, J. Struct. Geol., 74, 185-200, https://doi.org/10.1016/j.jsg.2015.03.003, 2015.

Buried Valleys: available at: https://buriedvalleys.dk/, last access: 25 May 2020.

Chilès, J.-P. and Delfiner, P.: Geostatistics, 2nd edn., John Wiley and Sons, Inc., Hoboken, NJ, USA, 2012.

Christiansen, A. V., Foged, N., and Auken, E.: A concept for calculating accumulated clay thickness from borehole lithological $\operatorname{logs}$ and resistivity models for nitrate vulnerability assessment, J. Appl. Geophys., 108, 69-77, https://doi.org/10.1016/j.jappgeo.2014.06.010, 2014.

Claerbout, J. F. and Abma, R.: Earth soundings analysis: Processing versus inversion. Vol. 6. London: Blackwell Scientific Publications, 1992.

Close, M. E., Abraham, P., Humphries, B., Lilburne, L., Cuthill, T., and Wilson, S. R.: Predicting groundwater redox status on a regional scale using linear discriminant analysis, J. Contam. Hydrol., 191, 19-32, https://doi.org/10.1016/j.jconhyd.2016.04.006, 2016.

Curtis, A.: The science of subjectivity, Geology, 40, 95-96, https://doi.org/10.1130/focus012012.1, 2012.

Dalgaard, T., Hansen, B., Hasler, B., Hertel, O., Hutchings, N. J., Jacobsen, B. H., Stoumann Jensen, L., Kronvang, B., Olesen, J. E., Schjørring, J. K., Sillebak Kristensen, I., Graversgaard, M., Termansen, M., and Vejre, H.: Policies for agricultural nitrogen management - trends, challenges and prospects for improved efficiency in Denmark, Environ. Res. Lett., 9, 115002, https://doi.org/10.1088/1748-9326/9/11/115002, 2014.

Danielsen, J. E., Auken, E., Jørgensen, F., Søndergaard, V. H., and Sørensen, K. I.: The application of the transient electromagnetic 
method in hydrogeophysical surveys, J. Appl. Geophys., 53, 181-198, https://doi.org/10.1016/j.jappgeo.2003.08.004, 2003.

de Vries, L. M., Carrera, J., Falivene, O., Gratacós, O., and Slooten, L. J.: Application of multiple point geostatistics to non-stationary images, Math. Geosci., 41, 29-42, https://doi.org/10.1007/s11004-008-9188-y, 2009.

Ephesia consult: DeeSse software, available at: https://www. ephesia-consult.com/portfolio/deesse/, last access: 18 May 2021.

Ernstsen, V. and von Platen, F.: GEUS Rapport 2014/20: Opdatering af det nationale redoxkort fra 2006, GEUS, report, Copenhagen, Denmark, 2014.

Ernstsen, V., von Platen, F., and Jakobsen, P. R.: GEUS Rapport 2008/30: Nitratreduktionsklasser for kystnære arealer ("hvide områder") - data og metode, Supplement til GEUS rapport 2006/93, GEUS, Copenhagen, Denmark, 2008.

European Commission: Report from the Commission to the Council and the European Parliament on the implementation of Council Directive 91/676/EEC concerning the protection of waters against pollution caused by nitrates from agricultural sources based on Member State reports fo, available at: https://eur-lex.europa.eu/legal-content/EN/TXT/PDF/ ?uri=CELEX:52018DC0257\&from=en (last access: 15 May 2021), 2018.

Foged, N., Marker, P. A., Christansen, A. V., Bauer-Gottwein, P., Jørgensen, F., Høyer, A.-S., and Auken, E.: Large-scale 3-D modeling by integration of resistivity models and borehole data through inversion, Hydrol. Earth Syst. Sci., 18, 4349-4362, https://doi.org/10.5194/hess-18-4349-2014, 2014.

GERDA, GEUS: National geophysical database, available at: https://eng.geus.dk/products-services-facilities/data-and-maps/ national-geophysical-database-gerda, last access: 18 May 2021.

Goovaerts, P., AvRuskin, G., Meliker, J., Slotnick, M., Jacquez, G., and Nriagu, J.: Geostatistical modeling of the spatial variability of arsenic in groundwater of southeast Michigan, Water Resour. Res., 41, 1-19, https://doi.org/10.1029/2004WR003705, 2005.

Gravesen, P. and Fredericia, J.: ZEUS-geodatabase system, Borearkivet, Databeskrivelse, kodesystem og sideregistre, 1984 (in Danish).

Gravey, M. and Mariethoz, G.: QuickSampling v1.0: a robust and simplified pixel-based multiple-point simulation approach, Geosci. Model Dev., 13, 2611-2630, https://doi.org/10.5194/gmd-13-2611-2020, 2020.

Grenthe, I., Stumm, W., Laaksuharju, M., Nilsson, A. C., and Wikberg, P.: Redox potentials and redox reactions in deep groundwater systems, Chem. Geol., 98, 131-150, https://doi.org/10.1016/0009-2541(92)90095-M, 1992.

Groffman, P. M., Butterbach-Bahl, K., Fulweiler, R. W., Gold, A. J., Morse, J. L., Stander, E. K., Tague, C., Tonitto, C., and Vidon, P.: Challenges to incorporating spatially and temporally explicit phenomena (hotspots and hot moments) in denitrification models, Biogeochemistry, 93, 49-77, https://doi.org/10.1007/s10533-008-9277-5, 2009.

Guardiano, F. B. and Srivastava, R. M.: Multivariate Geostatistics: Beyond Bivariate Moments, in: Geostatistics Tróia '92. Quantitative Geology and Geostatistics, edited by: Soares, A., Springer, Dordrecht, 133-144, 1993.

Gulbrandsen, M. L., Cordua, K. S., Bach, T., and Hansen, T. M.: Smart Interpretation - automatic geological interpretations based on supervised statistical models, Comput. Geosci., 21, 427-440, https://doi.org/10.1007/s10596-017-9621-8, 2017.

Gunnink, J. L. and Siemon, B.: Applying airborne electromagnetics in 3D stochastic geohydrological modelling for determining groundwater protection, Near Surf. Geophys., 13, 45-60, https://doi.org/10.3997/1873-0604.2014044, 2015.

Hansen, A. L., Christensen, B. S. B., Ernstsen, V., He, X., and Refsgaard, J. C.: A concept for estimating depth of the redox interface for catchment-scale nitrate modelling in a till area in Denmark, Hydrogeol. J., 22, 1639-1655, https://doi.org/10.1007/s10040014-1152-y, 2014.

Hansen, B., Sonnenborg, T. O., Møller, I., Bernth, J., Høyer, A.S., Rasmussen, P., Sandersen, P. B. E., and Jørgensen, F.: Nitrate vulnerability assessment of aquifers, Environ. Earth Sci., 75, 999, https://doi.org/10.1007/s12665-016-5767-2, 2016.

Hansen, B., Thorling, L., Schullehner, J., Termansen, M., and Dalgaard, T.: Groundwater nitrate response to sustainable nitrogen management, Sci. Rep.-UK, 7, 8566, 1-12, https://doi.org/10.1038/s41598-017-07147-2, 2017.

Hansen, B., Thorling, L., Kim, H., and Blicher-Mathiesen, G.: Long-term nitrate response in shallow groundwater to agricultural N regulations in Denmark, J. Environ. Manage., 240, 6674, https://doi.org/10.1016/j.jenvman.2019.03.075, 2019.

Hansen, B., Voutchkova, D. D., Sandersen, P. B. E., Kallesøe, A., Thorling, L., Møller, I., Madsen, R. B., Jakobsen, R., Aamand, J., Maurya, P., and Kim, H.: Assessment of complex subsurface redox structures for sustainable development of agriculture and the environment, Environ. Res. Lett., 16, 025007, https://doi.org/10.1088/1748-9326/abda6d, 2021.

Hansen, M. and Pjetursson, B.: Free, online Danish shallow geological data, Geol. Surv. Den. Greenl., 23, 53-56, https://doi.org/10.34194/geusb.v23.4842, 2011.

Hansen, T. M.: Entropy and Information Content of Geostatistical Models, Math. Geosci., 53, 163-184, https://doi.org/10.1007/s11004-020-09876-z, 2021.

Hansen, T. M., Cordua, K. S., Jacobsen, B. H., and Mosegaard, K.: Accounting for imperfect forward modeling in geophysical inverse problems - Exemplified for crosshole tomography, Geophysics, 79, H1-H21, https://doi.org/10.1190/GEO2013-0215.1, 2014.

Hansen, T. M., Vu, L. T., and Bach, T.: MPSLIB: A C++ class for sequential simulation of multiple-point statistical models, SoftwareX, 5, 127-133, https://doi.org/10.1016/j.softx.2016.07.001, 2016.

Hansen, T. M., Vu, L. T., Mosegaard, K., and Cordua, K. S.: Multiple point statistical simulation using uncertain (soft) conditional data, Comput. Geosci., 114, 1-10, https://doi.org/10.1016/j.cageo.2018.01.017, 2018.

He, X., Koch, J., Sonnenborg, T. O., Jørgensen, F., Schamper, C., and Christian Refsgaard, J.: Transition probabilitybased stochastic geological modeling using airborne geophysical data and borehole data, Water Resour. Res., 50, 3147-3169, https://doi.org/10.1002/2013WR014593, 2014.

He, X., Højberg, A. L., Jørgensen, F., and Refsgaard, J. C.: Assessing hydrological model predictive uncertainty using stochastically generated geological models, Hydrol. Process., 29, 42934311, https://doi.org/10.1002/hyp.10488, 2015.

He, X. L., Sonnenborg, T. O., Jørgensen, F., and Jensen, K. H.: The effect of training image and secondary data integration with 
multiple-point geostatistics in groundwater modelling, Hydrol. Earth Syst. Sci., 18, 2943-2954, https://doi.org/10.5194/hess-182943-2014, 2014.

Hoffimann, J., Scheidt, C., Barfod, A. S., and Caers, J.: Stochastic simulation by image quilting of processbased geological models, Comput. Geosci., 106, 18-32, https://doi.org/10.1016/j.cageo.2017.05.012, 2017.

Høyer, A.-S., Jørgensen, F., Sandersen, P. B. E., Viezzoli, A., and Møller, I.: 3D geological modelling of a complex buried-valley network delineated from borehole and AEM data, J. Appl. Geophys., 122, 94-102, https://doi.org/10.1016/j.jappgeo.2015.09.004, 2015.

Høyer, A.-S., Vignoli, G., Hansen, T. M., Vu, L. T., Keefer, D. A., and Jørgensen, F.: Multiple-point statistical simulation for hydrogeological models: 3-D training image development and conditioning strategies, Hydrol. Earth Syst. Sci., 21, 6069-6089, https://doi.org/10.5194/hess-21-6069-2017, 2017.

GEUS: GEUS Maps of Denmark, available at: https://eng.geus.dk/ products-services-facilities/data-and-maps/maps-of-denmark/, last access: 25 May 2020.

Jakobsen, P. R. and Tougaard, L.: Danmarks digitale jordartskort $1: 25000$ Version 5.0, GEUS, Copenhagen, Denmark, 2020 (in Danish).

Jessell, M. W., Aillères, L., and de Kemp, E. A.: Towards an integrated inversion of geoscientific data: What price of geology?, Tectonophysics, 490, 294-306, https://doi.org/10.1016/j.tecto.2010.05.020, 2010.

Jørgensen, F. and Sandersen, P. B. E.: Buried and open tunnel valleys in Denmark-erosion beneath multiple ice sheets, Quaternary. Sci. Rev., 25, 1339-1363, https://doi.org/10.1016/j.quascirev.2005.11.006, 2006.

Jørgensen, F., Møller, R. R., Nebel, L., Jensen, N. P., Christiansen, A. V., and Sandersen, P. B. E.: A method for cognitive 3D geological voxel modelling of AEM data, B. Eng. Geol. Environ., 72, 421-432, https://doi.org/10.1007/s10064-013-0487-2, 2013.

Jørgensen, F., Høyer, A.-S., Sandersen, P. B. E., He, X., and Foged, N.: Combining 3D geological modelling techniques to address variations in geology, data type and density - An example from Southern Denmark, Comput. Geosci., 81, 53-63, https://doi.org/10.1016/j.cageo.2015.04.010, 2015.

Journel, A. and Zhang, T.: The necessity of a multiplepoint prior model, Math. Geol., 38, 591-610, https://doi.org/10.1007/s11004-006-9031-2, 2006.

Journel, A. G. and Huijbregts, C. J.: Mining Geostatistics, 1st edn., Academic Press, Inc., London, 1978.

Juda, P., Renard, P., and Straubhaar, J.: A Framework for the CrossValidation of Categorical Geostatistical Simulations, Earth Space Sci., 7, 1-17, https://doi.org/10.1029/2020EA001152, 2020.

Jupiter, GEUS: National geophysical database, available at: https://eng.geus.dk/products-services-facilities/data-and-maps/ national-well-database-jupiter, last access: 18 May 2021.

Kallis, G. and Butler, D.: The EU water framework directive: Measures and implications, Water Policy, 3, 125-142, https://doi.org/10.1016/S1366-7017(01)00007-1, 2001.

Keaton, J. R. and Degraff, J. V.: Surface observation and geologic mapping, Spec. Rep. - Natl. Res. Counc. Transp. Res. Board, 247 (January 1996), National academy Press, Washington D.C., USA, 178-230, 1996.
Keefer, D. A.: A Framework and Methods for Characterizing Uncertainty in Geologic Maps, edited by: Thorleifson, L. H., Berg, R. C., and Russel, H., Three Dimens. Geol. Mapp. Groundw. Appl. Minnesota Geol. Surv. Open File Rep., Minnesota Geological Survey, Minnesota, USA, 07-4, 2007.

Kim, H., Høyer, A.-S., Jakobsen, R., Thorling, L., Aamand, J., Maurya, P. K., Christiansen, A. V., and Hansen, B.: $3 \mathrm{D}$ characterization of the subsurface redox architecture in complex geological settings, Sci. Total Environ., 693, https://doi.org/10.1016/j.scitotenv.2019.133583, 2019.

Koch, J., Stisen, S., Refsgaard, J. C., Ernstsen, V., Jakobsen, P. R., and Højberg, A. L.: Modeling Depth of the Redox Interface at High Resolution at National Scale Using Random Forest and Residual Gaussian Simulation, Water Resour. Res., 55, 14511469, https://doi.org/10.1029/2018WR023939, 2019.

Lee, J., Jang, C., Wang, S., Liang, C., and Liu, C.: Delineation of spatial redox zones using discriminant analysis and geochemical modelling in arsenic-affected alluvial aquifers, Hydrol. Process., 22, 3029-3041, https://doi.org/10.1002/hyp.6884, 2008.

Lin, Y. P.: Simulating Spatial Distributions, Variability and Uncertainty of Soil Arsenic by Geostatistical Simulations in Geographic Information Systems, Open Environ. Sci., 2, 26-33, https://doi.org/10.2174/1876325100802010026, 2008.

Lindsay, M. D., Aillères, L., Jessell, M. W., de Kemp, E. A., and Betts, P. G.: Locating and quantifying geological uncertainty in three-dimensional models: Analysis of the Gippsland Basin, southeastern Australia, Tectonophysics, 546-547, 10-27, https://doi.org/10.1016/j.tecto.2012.04.007, 2012.

Loke, M. H., Chambers, J. E., Rucker, D. F., Kuras, O., and Wilkinson, P. B.: Recent developments in the direct-current geoelectrical imaging method, J. Appl. Geophys., 95, 135-156, https://doi.org/10.1016/j.jappgeo.2013.02.017, 2013.

Madsen, R. B: Replication Data for: Running MPS simulations of geology and redox in LOOP3 catchment area, Denmark, GEUS Dataverse, V1, https://doi.org/10.22008/FK2/XBQURH, 2021.

Madsen, R. B. and Hansen, T. M.: Estimation and accounting for the modeling error in probabilistic linearized AVO inversion, Geophysics, 83, N15-N30, https://doi.org/10.1190/geo2017-0404.1, 2018.

Madsen, R. B., Nørmark, E., and Hansen, T. M.: Accounting for Processing Errors in AVO/AVA Data, in: 80th EAGE Conference and Exhibition Proceedings, EAGE, 11-14 June, Copenhagen, Denmark, 5, 2018.

Madsen, R. B., Møller, I., and Hansen, T. M.: Choosing between Gaussian and MPS simulation: the role of data information content - a case study using uncertain interpretation data points, Stoch. Env. Res. Risk A., 2, https://doi.org/10.1007/s00477-02001954-2, 2021.

Malinverno, A. and Briggs, V. A.: Expanded uncertainty quantification in inverse problems: Hierarchical Bayes and empirical Bayes, Geophysics, 69, 1005-1016, https://doi.org/10.1190/1.1778243, 2004.

Maps of Denmark, GEUS: Maps of Denmark, available at: https://eng.geus.dk/products-services-facilities/data-and-maps/ maps-of-denmark/pricelist, last access: 18 May 2021).

Mariethoz, G. and Caers, J.: Multiple-point geostatistics: Stochastic modeling with training images, 1st edn., John Wiley and Sons, Chichester, UK, 2015. 
Mariethoz, G., Renard, P., and Straubhaar, J.: The direct sampling method to perform multiple-point geostatistical simulations, Water Resour. Res., 46, 1-14, https://doi.org/10.1029/2008WR007621, 2010.

Mariethoz, G., Straubhaar, J., Renard, P., Chugunova, T., and Biver, P.: Constraining distance-based multipoint simulations to proportions and trends, Environ. Model. Softw., 72, 184-197, https://doi.org/10.1016/j.envsoft.2015.07.007, 2015.

Møller, I., Søndergaard, V. H., and Jørgensen, F.: Geophysical methods and data administration in Danish groundwater mapping, Geol. Surv. Den. Greenl., 17, 41-44, https://doi.org/10.34194/geusb.v17.5010, 2009.

Nolan, B. T., Fienen, M. N., and Lorenz, D. L.: A statistical learning framework for groundwater nitrate models of the Central Valley, California, USA, J. Hydrol., 531, 902-911, https://doi.org/10.1016/j.jhydrol.2015.10.025, 2015.

Pyrcz, M. J., Boisvert, J. B., and Deutsch, C. V.: A library of training images for fluvial and deepwater reservoirs and associated code, Comput. Geosci., 34, 542-560, https://doi.org/10.1016/j.cageo.2007.05.015, 2008.

Randle, C. H., Bond, C. E., Lark, R. M., and Monaghan, A. A.: Uncertainty in geological interpretations: Effectiveness of expert elicitations, Geosphere, 15, 108-118, https://doi.org/10.1130/GES01586.1, 2019.

Ransom, K. M., Nolan, B. T., A. Traum, J., Faunt, C. C., Bell, A. M., Gronberg, J. A. M., Wheeler, D. C., Z. Rosecrans, C., Jurgens, B., Schwarz, G. E., Belitz, K., M. Eberts, S., Kourakos, G., and Harter, T.: A hybrid machine learning model to predict and visualize nitrate concentration throughout the Central Valley aquifer, California, USA, Sci. Total Environ., 601-602, 11601172, https://doi.org/10.1016/j.scitotenv.2017.05.192, 2017.

Rosecrans, C. Z., Nolan, B. T., and Gronberg, J. A. M.: Prediction and visualization of redox conditions in the groundwater of Central Valley, California, J. Hydrol., 546, 341-356, https://doi.org/10.1016/j.jhydrol.2017.01.014, 2017.

Sandersen, P. B. E.: Uncertainty assessment of geological models - A qualitative approach, in: Calibration and Reliability in Groundwater Modelling: Credibility of Modelling, edited by: Refsgaard, J. C., Kovar, K., Haarder, E., and Nygaard, E., IAHS Redbook ModelCARE 2007, Copenhagen, Denmark, 345-349, 2008.

Sandersen, P. B. E. and Jørgensen, F.: Kortlægning af begravede dale i Danmark [Mapping of Buried Valleys in Denmark], Opdatering 2015 (Update 2015), Vol. 1 and 2, GEUS Special Publication, Copenhagen, Denmark, 2016 (in Danish).

Sandersen, P. B. E., and Jørgensen, F.: Buried tunnel valleys in Denmark and their impact on the geological architecture of the subsurface, Geol. Surv. Den. Greenl., 38, 13-16, https://doi.org/10.34194/geusb.v38.4388, 2017.

Sandersen, P. B. E., Jørgensen, F., Larsen, N. K., Westergaard, J. H., and Auken, E.: Rapid tunnel-valley formation beneath the receding Late Weichselian ice sheet in Vendsyssel, Denmark, Boreas, 38, 834-851, https://doi.org/10.1111/j.1502-3885.2009.00105.x, 2009.

Schaaf, A. and Bond, C. E.: Quantification of uncertainty in 3-D seismic interpretation: implications for deterministic and stochastic geomodeling and machine learning, Solid Earth, 10, 1049-1061, https://doi.org/10.5194/se-10-1049-2019, 2019.
Schamper, C., Jørgensen, F., Auken, E., and Effersø, F.: Assessment of near-surface mapping capabilities by airborne transient electromagnetic data - An extensive comparison to conventional borehole data, Geophysics, 79, B187-B199, https://doi.org/10.1190/geo2013-0256.1, 2014.

Schullehner, J. and Hansen, B.: Nitrate exposure from drinking water in Denmark over the last 35 years, Environ. Res. Lett., 9, 095001, https://doi.org/10.1088/1748-9326/9/9/095001, 2014.

Schullehner, J., Hansen, B., Thygesen, M., Pedersen, C. B., and Sigsgaard, T.: Nitrate in drinking water and colorectal cancer risk: A nationwide population-based cohort study, Int. J. Cancer, 143, 73-79, https://doi.org/10.1002/ijc.31306, 2018.

SDFE: The Danish Map Supply, available at: https: //kortforsyningen.dk/indhold/english, last access: 18 May 2021.

Sexstone, A. J., Revsbech, N. P., Parkin, T. B., and Tiedje, J. M.: Direct Measurement of Oxygen Profiles and Denitrification Rates in Soil Aggregates, Soil Sci. Soc. Am. J., 49, 645-651, https://doi.org/10.2136/sssaj1985.03615995004900030024x, 1985.

Shannon, C. E.: A Mathematical Theory of Communication, Bell Syst. Tech. J., 27, 623-656, https://doi.org/10.1002/j.15387305.1948.tb00917.x, 1948.

Sørensen, K. I. and Auken, E.: SkyTEM - a new high-resolution helicopter transient electromagnetic system, Explor. Geophys., 35, 194-202, https://doi.org/10.1071/EG04194, 2004.

Straubhaar, J.: DeeSse User's Guide, The Centre for Hydrogeology and Geothermics (CHYN), University of Neuchatel, Neuchâtel, Switzerland, 2019.

Straubhaar, J., Renard, P., Mariethoz, G., Froidevaux, R., and Besson, O.: An improved parallel multiple-point algorithm using a list approach, Math. Geosci., 43, 305-328, https://doi.org/10.1007/s11004-011-9328-7, 2011.

Strebelle, S.: Conditional Simulation of Complex Geological Structures Using Multiple-Point Statistics, Math. Geol., 34, 1-21, https://doi.org/10.1109/CEC.2011.5949612, 2002.

Strebelle, S.: Multiple-Point Geostatistics: from Theory to Practice, in: Expanded Abstract Collection from Ninth International Geostatistics Congress, 11-15 June, Oslo, Norway, 1-65, 2012.

Styrelsen for Dataforsyning og Effektivisering: Danmarks Højdemodel, DHM/Terræn. Data version 2.0 - Januar 2015, available at: https://www.kortforsyningen.dk/sites/default/files/dk dhm_terraen_v2_1_aug_2016.pdf (last access: 15 May 2021), 2016 (in Danish).

Tahmasebi, P.: Multiple Point Statistics: A Review, in: Handbook of Mathematical Geosciences, edited by: Daya Sagar, B. S., Cheng, Q., and Agterberg, F., Springer International Publishing, Cham, 613-643, 2018.

Tahmasebi, P., Hezarkhani, A., and Sahimi, M.: Multiple-point geostatistical modeling based on the cross-correlation functions, Comput. Geosci., 16, 779-797, https://doi.org/10.1007/s10596012-9287-1, 2012.

Tarantola, A.: Inverse problem theory and Methods for Model Parameter Estimation, 1st edn., SIAM, Philadelphia, USA, 2005.

Temkin, A., Evans, S., Manidis, T., Campbell, C., and Naidenko, O. V.: Exposure-based assessment and economic valuation of adverse birth outcomes and cancer risk due to nitrate in United States drinking water, Environ. Res., 176, 1-14, https://doi.org/10.1016/j.envres.2019.04.009, 2019. 
Tesoriero, A. J., Terziotti, S., and Abrams, D. B.: Predicting Redox Conditions in Groundwater at a Regional Scale, Environ. Sci. Technol., 49, 9657-9664, https://doi.org/10.1021/acs.est.5b01869, 2015.

Thomsen, R., Søndergaard, V. H., and Sørensen, K. I.: Hydrogeological mapping as a basis for establishing site-specific groundwater protection zones in Denmark, Hydrogeol. J., 12, 550-562, https://doi.org/10.1007/s10040-004-0345-1, 2004.

Vest Christiansen, A. and Auken, E.: A global measure for depth of investigation, Geophysics, 77, WB171-WB177, https://doi.org/10.1190/geo2011-0393.1, 2012.

Viezzoli, A., Christiansen, A. V., Auken, E., and Sørensen, K. I.: Quasi-3D modeling of airborne TEM data by spatially constrained inversion, Geophysics, 73, F105-F113, https://doi.org/10.1190/1.2895521, 2008.

Viezzoli, A., Jørgensen, F., and Sørensen, C.: Flawed processing of airborne em data affecting hydrogeological interpretation, Groundwater, 51, 191-202, https://doi.org/10.1111/j.17456584.2012.00958.x, 2013.

Vignoli, G., Fiandaca, G., Christiansen, A. V., Kirkegaard, C., and Auken, E.: Sharp spatially constrained inversion with applications to transient electromagnetic data, Geophys. Prospect., 63, 243-255, https://doi.org/10.1111/1365-2478.12185, 2015.

Vilhelmsen, T. N., Auken, E., Christiansen, A. V., Barfod, A. S., Marker, P. A., and Bauer-Gottwein, P.: Combining Clustering Methods With MPS to Estimate Structural Uncertainty for Hydrological Models, Front. Earth Sci., 7, 1-15, https://doi.org/10.3389/feart.2019.00181, 2019.

Wellmann, J. F. and Caumon, G.: 3-D Structural geological models: Concepts, methods, and uncertainties, 1st edn., Elsevier Inc., London, UK, 2018.
Wellmann, J. F., De La Varga, M., Murdie, R. E., Gessner, K., and Jessell, M. W.: Uncertainty estimation for a geological model of the Sandstone greenstone belt, Western Australia - insights from integrated geological and geophysical inversion in a Bayesian inference framework, Geol. Soc. Spec. Publ., 453, 4156, https://doi.org/10.1144/SP453.12, 2018.

Wilkin, R. T., Barnes, H. L., and Brantley, S. L.: The size distribution of framboidal pyrite in modern sediments, Geochim. Cosmochim. Ac., 60, 3897-3912, 1996.

Wilson, C. G., Bond, C. E., and Shipley, T. F.: How can geologic decision-making under uncertainty be improved?, Solid Earth, 10, 1469-1488, https://doi.org/10.5194/se-10-1469-2019, 2019.

Wilson, S. R., Close, M. E., and Abraham, P.: Applying linear discriminant analysis to predict groundwater redox conditions conducive to denitrification, J. Hydrol., 556, 611-624, https://doi.org/10.1016/j.jhydrol.2017.11.045, 2018.

Wycisk, P., Hubert, T., Gossel, W., and Neumann, C.: Highresolution 3D spatial modelling of complex geological structures for an environmental risk assessment of abundant mining and industrial megasites, Comput. Geosci., 35, 165-182, https://doi.org/10.1016/j.cageo.2007.09.001, 2009.

Yan, S., Liu, Y., Liu, C., Shi, L., Shang, J., Shan, H., Zachara, J., Fredrickson, J., Kennedy, D., Resch, C. T., Thompson, C., and Fansler, S.: Nitrate bioreduction in redox-variable low permeability sediments, Sci. Total Environ., 539, 185-195, https://doi.org/10.1016/j.scitotenv.2015.08.122, 2016. 